\title{
Phase transitions of multivalent proteins can promote clustering of membrane receptors
}

\author{
Sudeep Banjade, Michael K Rosen* \\ Department of Biophysics, Howard Hughes Medical Institute, University of Texas \\ Southwestern Medical Center, Dallas, United States
}

\begin{abstract}
Clustering of proteins into micrometer-sized structures at membranes is observed in many signaling pathways. Most models of clustering are specific to particular systems, and relationships between physical properties of the clusters and their molecular components are not well understood. We report biochemical reconstitution on supported lipid bilayers of protein clusters containing the adhesion receptor Nephrin and its cytoplasmic partners, Nck and N-WASP. With Nephrin attached to the bilayer, multivalent interactions enable these proteins to polymerize on the membrane surface and undergo two-dimensional phase separation, producing micrometer-sized clusters. Dynamics and thermodynamics of the clusters are modulated by the valencies and affinities of the interacting species. In the presence of the Arp2/3 complex, the clusters assemble actin filaments, suggesting that clustering of regulatory factors could promote local actin assembly at membranes. Interactions between multivalent proteins could be a general mechanism for cytoplasmic adaptor proteins to organize membrane receptors into micrometer-scale signaling zones.
\end{abstract}

DOI: 10.7554/eLife.04123.001

*For correspondence: michael. rosen@utsouthwestern.edu

Competing interests: The authors declare that no competing interests exist.

Funding: See page 21

Received: 22 July 2014

Accepted: 16 October 2014

Published: 16 October 2014

Reviewing editor: Anthony A Hyman, Max Planck Institute of Molecular Cell Biology and Genetics, Germany

(c) Copyright Banjade and Rosen. This article is distributed under the terms of the Creative Commons Attribution License, which permits unrestricted use and redistribution provided that the original author and source are credited.

\section{Introduction}

Numerous membrane proteins have been observed to organize into supramolecular clusters upon extracellular ligand binding and/or cell-cell adhesion. Examples include cadherins (Yap et al., 1997), Eph receptors (Nikolov et al., 2013; Seiradake et al., 2013), immune receptors (Goldstein and Perelson, 1984), apoptotic signaling receptors (Henkler et al., 2005), chemotaxis receptors (Li et al., 2011), GPI anchored proteins (Varma and Mayor, 1998) and components of T cell signaling pathways (Balagopalan et al., 2013). A variety of mechanisms have been proposed to account for this higherorder organization. The extracellular domains of cadherins and Eph receptors have been postulated to interact laterally in homotypic fashion within the plasma membrane to produce large-scale assemblies at sites of cell-cell adhesion (Himanen et al., 2007; Wu et al., 2011; Seiradake et al., 2013). Modeling studies have suggested that binding of divalent antibodies to the extracellular domain of trivalent FcE receptors could lead to large networks, which could account for FcE receptor puncta observed in cells (Goldstein and Perelson, 1984). An analogous mechanism has been proposed for intracellular interactions of the oligomeric receptor, Fas, with its oligomeric adaptor protein FADD (Scott et al., 2009; Wang et al., 2010; $\mathrm{Wu}, 2013)$ to produce clusters of the receptors hundreds of nanometers in size (Siegel et al., 2004). Similarly, dimeric bacterial chemoreceptors such as Tsr are linked together by their downstream partners CheA and CheW, forming trimers of dimers resulting in a highly ordered and conserved hexagonal array that is suggested to be the basic unit of polar clusters (Briegel et al., 2012, 2014). GPI-anchored proteins and lipid-anchored Ras have been shown to organize into dynamic clusters of 4-7 molecules through transient interactions with lipids and the cortical actin-myosin network (Plowman et al., 2005; Goswami et al., 2008). Such clusters of GPI-anchored proteins are also believed to play an important role in creation of dynamic nanometer scale cholesterol-rich lipid domains, which further contribute to organization of the plasma membrane (Sharma et al., 2004; 
eLife digest The membrane that surrounds a cell is made up of a mixture of lipid molecules and proteins. Membrane proteins perform a wide range of roles, including transmitting signals into, and out of, cells and helping neighboring cells to stick together. To perform these tasks, these proteins commonly need to bind to other molecules-collectively known as ligands-that are found either inside or outside the cell.

Membrane proteins are able to move around within the membrane, and in many systems, ligand binding causes the membrane proteins to cluster together. Although this clustering has been seen in many different systems, no general principles that describe how clustering occurs had been found.

Now, Banjade and Rosen have constructed an artificial cell membrane to investigate the clustering of a membrane protein called Nephrin, which is essential for kidneys to function correctly. When it is activated, Nephrin interacts with protein ligands called Nck and N-WASP that are found inside cells and helps filaments of a protein called actin to form. These filaments perform a number of roles including enabling cells to adhere to each other and to move.

In Banjade and Rosen's artificial system, when a critical concentration of ligands was exceeded, clusters of Nephrin, Nck and N-WASP suddenly formed. This suggests that the clusters form through a physical process known as 'phase separation'. Banjade and Rosen found that this critical concentration depends on how strongly the proteins interact and the number of sites they possess to bind each other.

Within the clusters, the three proteins formed large polymer chains. The clusters were mobile and, over time, small clusters coalesced into larger clusters. Even though the clusters persisted for hours, individual proteins did not stay in a given cluster for long and instead continuously exchanged back-and-forth between the cluster and its surroundings.

When actin and another protein complex that interacts with N-WASP were added to the artificial membrane system, actin filaments began to form at the protein clusters. Banjade and Rosen suggest that such clusters act as 'signaling zones' that coordinate the construction of the actin filaments. Regions that are also found in many other signaling proteins mediate the interactions between Nephrin, Nck and N-WASP. Banjade and Rosen therefore suggest that phase separation and protein polymer formation could explain how many different types of membrane proteins form clusters. DOI: 10.7554/eLife.04123.002

Lingwood and Simons, 2010; Gowrishankar et al., 2012). Finally, data suggest that clustering of $T$ cell receptors may arise in part from size differences, and consequent steric occlusion, between the extracellular domains of different membrane proteins found at contacts between $T$ cells and antigen presenting cells (James and Vale, 2012).

These models have proven powerful in describing the individual systems above. However, for several reasons most of them are difficult to generalize in a predictive manner to new systems. First, the models hinge on molecular interactions that are specific to the individual systems and that are not readily apparent from protein sequence features alone. Thus, with the exception of GPI-anchored proteins, which likely behave similarly as a group, in the absence of a fairly detailed physical characterization it is difficult to predict whether any new protein/system is likely to produce membrane clusters, and if so, which clustering models are most appropriate. Additionally, with the exception of the nanometer scale clusters of GPI-anchored proteins and lipid-modified Ras, the physical properties of most receptor clusters have not been extensively characterized. Clustering models have derived in many cases from molecular packing in crystal lattices and have been analyzed largely through cellular studies showing qualitative consistency with structural studies and theoretical analyses. But in general, the physical properties of the clusters (e.g., their thermodynamic and kinetic properties) have not been correlated to the physical parameters of the molecules that compose them nor have the key molecular properties that influence cluster properties been identified. This shortcoming arises partly because the models have not been examined through in vitro biochemical reconstitution, where the parameters of the system can be tightly controlled and the physical properties of the clusters can be analyzed in detail. Finally, the functional consequences of macroscopic clustering (as distinct from association to create defined oligomers-dimers, trimers, etc) are not well understood. But it is notable that many clustered receptors signal to the actin cytoskeleton, and that many of their downstream targets, such 
as actin nucleation promoting factors in the WASP family, are also known to form micrometer sized clusters at the plasma membrane (Yamaguchi et al., 2005; Weiner et al., 2007; Gomez and Billadeau, 2009). These observations suggest that one function of receptor clustering may be to control the localization, structure, and/or dynamics of actin filament networks.

We recently demonstrated that interactions between multivalent proteins and their multivalent ligands can lead to macroscopic phase separation. This occurs concomitant with assembly of the proteins into large polymers, through a sol-gel transition, as observed in many other multivalent systems in polymer science (Li et al., 2012). In three-dimensional solution, this process produces phase separated protein polymers that organize into dynamic micron sized liquid droplets. These droplets are formed in a sharp transition as protein concentration in solution is increased. The critical concentration for droplet formation depends on valency and affinity of interacting species, and the proteins are highly concentrated within the droplets. We have studied this phenomenon in a variety of model multivalent systems, involving both protein-protein and protein-RNA interactions, and also in an actin regulatory signaling pathway involving the adhesion receptor, Nephrin, and its intracellular targets Nck and N-WASP (Jones et al., 2006). In the latter, phase separation can be controlled by multivalent phosphorylation of Nephrin and results in enhanced signaling activity of N-WASP.

These previous studies were performed in three-dimensional solution. But in vivo Nephrin is an integral membrane protein; therefore its cytoplasmic tail is attached to membranes (Welsh and Saleem, 2010). The behavior of multivalent-multivalent interaction systems in such a two-dimensional arrangement remained unresolved. In this study, we show that multivalency-induced polymerization and phase separation can also occur in two-dimensional systems, generating micrometer-size protein clusters at membranes. When phosphorylated Nephrin is attached to supported lipid bilayers of DOPC, addition of Nck and N-WASP induce formation of micron-sized concentrated puncta containing all three proteins. Puncta form abruptly when a critical concentration of Nck/N-WASP is reached and are highly dynamic. The critical concentration is appreciably lower for two-dimensional puncta formation than for three-dimensional droplet formation, and it depends on the phosphotyrosine and $\mathrm{SH} 3$ domain valencies of p-Nephrin and Nck, respectively, and also on the affinity of the Nck SH2 domain for $\mathrm{p}-\mathrm{Nephrin}$. These data suggest that puncta formation is driven by polymerization of the proteins in a plane adjacent to the membrane. In the presence of actin and the N-WASP target, the Arp2/3 complex, puncta formation causes focal actin assembly. Our biochemical approach has allowed us to control the clustering process and discover key parameters that control puncta formation. Our study demonstrates that specific protein-protein interactions result in the formation of macroscopic clusters without the necessity of lipid segregation or actin-myosin assembly. This clustering can be defined as phase separation of proteins on the surface of a membrane. Our observations here and previously (Li et al., 2012) suggest that polymerization and phase separation of multivalent macromolecules may represent a general mechanism to produce two- and three-dimensional dynamic and highly concentrated micron-sized structures in cells.

\section{Results}

\section{Membrane-bound $p$-Nephrin clusters through a phase transition upon addition of Nck and N-WASP}

Nephrin is a transmembrane protein expressed in the foot processes of kidney podocyte cells, where its extracellular domain is a critical component of the slit diaphragm, the final element of the kidney's glomerular filtration barrier (Welsh and Saleem, 2010). The integrity of the slit diaphragm requires intracellular assembly of actin filaments downstream of the Nephrin cytoplasmic tail (Jones et al., 2006). When Nephrin is crosslinked by antibodies, its cytoplasmic tail can be phosphorylated by the Src family kinase, Fyn (Jones et al., 2006; Verma et al., 2006). Three phosphotyrosines (pTyrs) in the tail bind the SH2 domain of the Nck adaptor protein, which in turn uses its three $\mathrm{SH} 3$ domains to bind multiple proline-rich motifs (PRMs) in the actin regulatory protein, N-WASP. N-WASP then recruits and promotes activation of the Arp2/3 complex, which generates branched actin filament networks through nucleating new actin polymers. Mutations that disrupt this pathway in humans and mice result in disorganization of the slit diaphragm and defects in the glomerular filter that cause proteinuria (Jones et al., 2006, 2009).

We previously reported that mixing Nck, N-WASP, and the phosphorylated cytoplasmic tail of Nephrin in solution produced phase separated liquid droplets (Li et al., 2012). This observation suggested that if the Nephrin tail was attached to a membrane, as it is in vivo, Nck and N-WASP might 
induce it to condense into membrane clusters (Figure 1A). To test this hypothesis, we began by generating the triply phosphorylated cytoplasmic tail of Nephrin (amino acids 1174-1223, phosphorylated at Tyr1176, Tyr1193, and Tyr1217, and mutated from Tyr to Phe at residues 1183 and 1210, sites not believed to bind Nck (Jones et al., 2006; Verma et al., 2006); called p-Nephrin hereafter). The construct contained a His $s_{8}$ tag at its $\mathrm{N}$-terminus, followed by a (Gly-Gly-Ser) 5 linker containing a cysteine, which was covalently labeled with maleimide Alexa488 fluorophore. We attached p-Nephrin to supported bilayers of DOPC lipid, doped with $1 \%$ of a nickel-chelating lipid $\left(\mathrm{Ni}^{2+}-\mathrm{NTA}-\mathrm{DOGS}\right)$. Through this approach we could control and quantify the surface density of p-Nephrin as detailed in the 'Materials and methods' section (Galush et al., 2008).

Membrane-bound p-Nephrin is homogeneous and fluid on supported bilayers, as demonstrated by total internal reflection fluorescence microscopy (TIRFM) and rapid fluorescence recovery after photobleaching (FRAP, exponential recovery time constant $\mathrm{T}=1.3 \mathrm{~s}$ ) (Figure 1B, and Figure 1-figure supplement 1A). Addition of $1 \mu \mathrm{M}$ Nck causes no change in the distribution of $\mathrm{p}$-Nephrin on

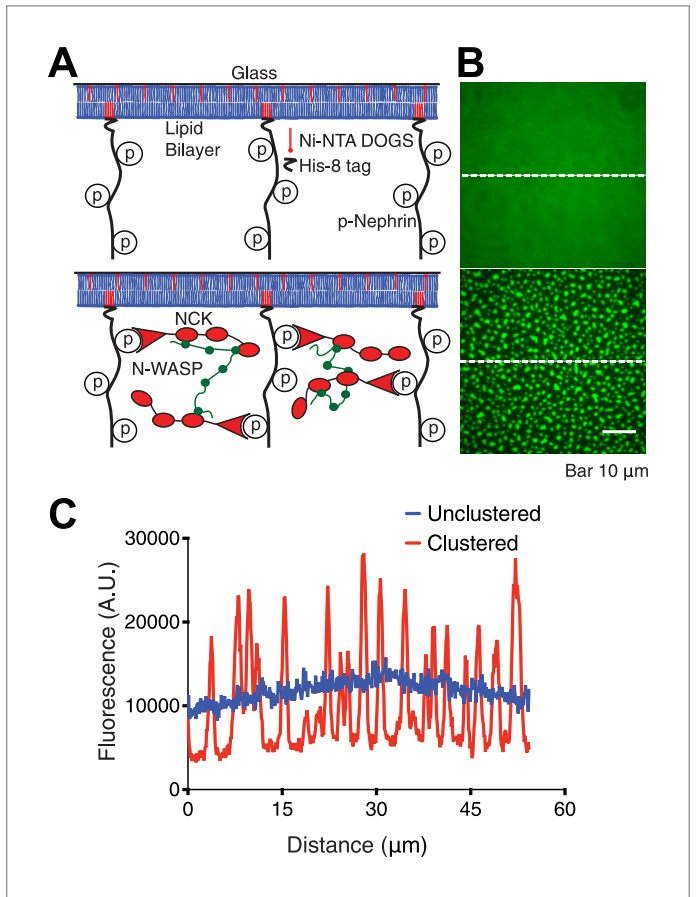

Figure 1. Reconstitution of $\mathrm{p}-\mathrm{Nephrin}$ clusters on supported lipid bilayers. (A) Cartoon illustrating the interaction of triply-phosphorylated His-tagged Nephrin (p-Nephrin) with its partners Nck and N-WASP. Top panel illustrates $\mathrm{p}$-Nephrin attached to bilayers. Bottom panel illustrates the model for clustered p-Nephrin, upon Nck and N-WASP binding. (B) Top: TIRF image of Alexa488labeled $\mathrm{p}-$ Nephrin attached to a supported DOPC lipid bilayer doped with $1 \%$ nickel-chelating lipid $\left(\mathrm{Ni}^{2+}-\mathrm{NTA}\right.$ DOGS), (corresponding to panel A, top). Bottom: TIRF image of analogous membrane-attached Alexa488labeled p-Nephrin after addition of $1 \mu \mathrm{M} \mathrm{Nck}$ and $1 \mu \mathrm{M} \mathrm{N}$-WASP (corresponding to panel $\mathbf{A}$, bottom). (C) Line-scans of the images in panel $\mathbf{B}$, at the positions depicted by the white dotted lines.

DOI: 10.7554/eLife.04123.003

The following figure supplement is available for figure 1

Figure supplement 1. p-Nephrin, Nck and N-WASP colocalize to clusters formed on fluid supported lipid bilayers.

DOI: 10.7554/eLife.04123.004 the membrane, despite clear association of Nck with the bilayer (Figure 1-figure supplement 1B). Similarly, $1 \mu \mathrm{M}$ of an N-WASP construct containing the basic proline-rich and VCA regions of the protein (residues 183-193, 273-501, N-WASP hereafter) does not change the $\mathrm{p}-\mathrm{Nephrin}$ distribution. However, addition of $1 \mu \mathrm{M} \mathrm{Nck}$ and $1 \mu \mathrm{M}$ $\mathrm{N}$-WASP together causes $\mathrm{p}-\mathrm{Nephrin}$ to organize into micron-sized clusters (Figure 1B, Video 1). Unphosphorylated Nephrin remains uniformly distributed under these conditions (not shown), indicating that clustering requires binding the Nck SH2 domain to pTyr sites on Nephrin. Labeling of Nck or N-WASP with fluorophores (Alexa 568 or Alexa 647, respectively) shows that the clusters contain all three protein components (Figure 1-figure supplement 1C). Quantitative analysis indicated that the clustered regions contain up to fourfold higher density of $\mathrm{p}$-Nephrin than the surrounding regions of the bilayer (Figure 1C). Note that much higher concentrations of Nck and N-WASP $(\sim 40 \mu \mathrm{M}$ and $\sim 15 \mu \mathrm{M}$, respectively [ Li et al., 2012]) are required to form phase-separated droplets in solution than to induce $\mathrm{p}$-Nephrin clustering on membranes. Thus, clustering does not involve adhesion of pre-existing three dimensional Nck/ $\mathrm{N}$-WASP droplets to membrane-bound p-Nephrin, but rather de novo assembly of the proteins together on the bilayer surface. Further, the DOPC/ DOGS lipids in our experiments do not phaseseparate, indicating that clustering is independent of lipid phase separation.

To understand the concentration dependence of cluster formation, we fixed the concentration of N-WASP at $500 \mathrm{nM}$ and the density of p-Nephrin at $2700 \pm 200$ molecules $/ \mu^{2}{ }^{2}$ (see density control and measurement in 'Materials and methods', also Figure 2-figure supplement 1, 2) and added increasing concentrations of Nck. We used two measures to determine the onset of clustering. First, we used a thresholding approach 


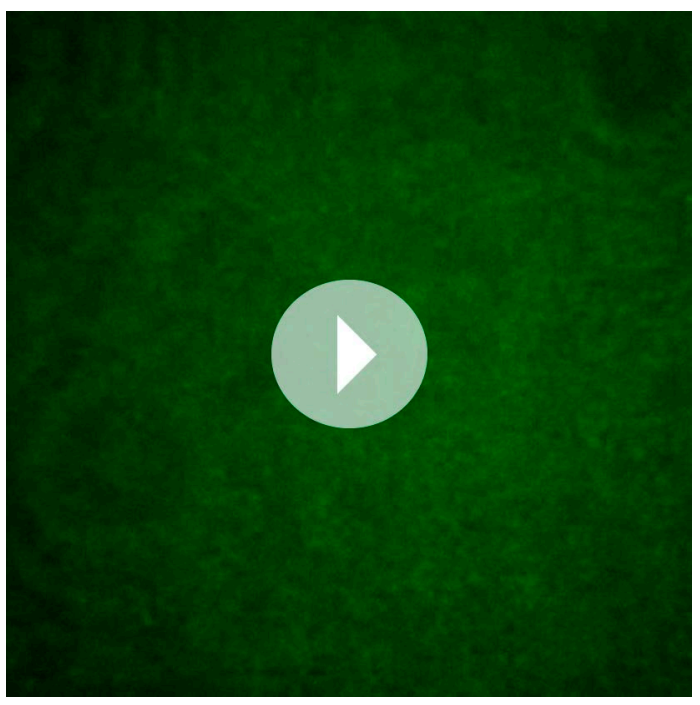

Video 1. Addition of Nck and N-WASP to p-Nephrin produces macroscopic clusters on supported bilayers. Time-lapse images taken immediately after adding $1 \mu \mathrm{M}$ Nck and $1 \mu \mathrm{M}$ N-WASP to p-Nephrin Alexa488. Images were captured every minute. DOI: 10.7554/eLife.04123.005 to identify and quantify bright regions of the membrane, which we define as clusters. As detailed in 'Materials and methods', two different thresholding procedures gave virtually identical results in this approach. After thresholding, we calculated the fraction of total membrane fluorescence intensity that is present in the clusters. As a second independent approach, we determined the variance of the fluorescence signal across the bilayer image, which also increases as bright regions form. Using either approach, we found that $\mathrm{p}$-Nephrin clusters appear in a highly nonlinear fashion as Nck concentration in solution increases. Clusters are essentially absent at low concentrations of Nck but form quite sharply once a critical concentration is reached ( $200 \mathrm{nM}$, Figure 2A). We note that the sharp increase in variance and the coincidence of the critical concentration measured by both methods speak against the possibility that small clusters are forming in a more gradual fashion but are too dim to be recognized by the thresholding approach. The average density of $\mathrm{p}$-Nephrin on the membrane does not change during the titration (Figure 2-figure supplement 2). We define the concentration at which fractional intensity and variance begin increasing as the clustering concentration. The highly cooperative nature of the cluster formation on bilayers is reminiscent of the sharp phase transitions observed in forming $\mathrm{p}-\mathrm{Nephrin/Nck/N-WASP}$ liquid droplets in three-dimensional solutions (Li et al., 2012). The clusters are distributed randomly (Gaussian distribution) across the membrane (Figure 2B), consistent with a stochastic assembly process, where the clusters are nucleated and grow independent of one other (Dill and Bromberg, 2003). The clusters also show a broad range of sizes that can be fit well to an exponential distribution (Figure 2C), similar to that observed for stochastically assembled chemotaxis receptors in bacteria (Greenfield et al., 2009). These properties suggest a stochastic process of cluster formation in our system. In contrast, clusters of GPI-anchored proteins in cells do not show a Gaussian spatial distribution nor a broad size distribution, indicating their active control by the cortical actin cytoskeleton (Goswami et al., 2008).

When experiments are performed at fivefold higher initial density of p-Nephrin on the membrane, the morphology of the clusters changes significantly. Distinct puncta are no longer observed, and the clustered regions span the entire field of view (Figure 2D). These data are consistent with low- and high-density $\mathrm{p}$-Nephrin phase separating via nucleation and spinodal decomposition mechanisms, respectively (Dill and Bromberg, 2003), as observed in non-biological phase separating systems in material science (Zinke-Allmang et al., 1992). Together, these data strongly suggest that the clustering of $\mathrm{p}$-Nephrin occurs through a phase transition of the molecules on the surface of the membrane in response to binding of Nck and N-WASP.

We next examined the dynamic behaviors of the p-Nephrin clusters. Individual clusters are irregularly shaped, indicating that they possess low line tension. On short timescales, the edges of clusters show substantial fluctuations, extending and retracting in seconds (Video 2). On timescales of minutes, these fluctuations lead to coalescence of small clusters into increasingly larger structures (Figure 3A, Videos 1, 2). We also rarely observe apparent fission events, where a larger cluster seems to split into two smaller structures (Video 2). These behaviors suggest that $\mathrm{p}$-Nephrin clusters are fluid-like. The size distribution of the clusters depends on the initial p-Nephrin density and time after Nck/N-WASP addition, reflecting variable contributions of nucleation, growth through monomer addition and coalescence, and Ostwald ripening throughout the process (Zinke-Allmang et al., 1992). At lower density $\left(2500\right.$ molecules $\left./ \mu \mathrm{m}^{2}\right)$ the distribution is exponential at all times we examined (Figure 3-figure supplement 1), while at higher density $\left(4000\right.$ molecules $\left./ \mu m^{2}\right)$ the distribution 


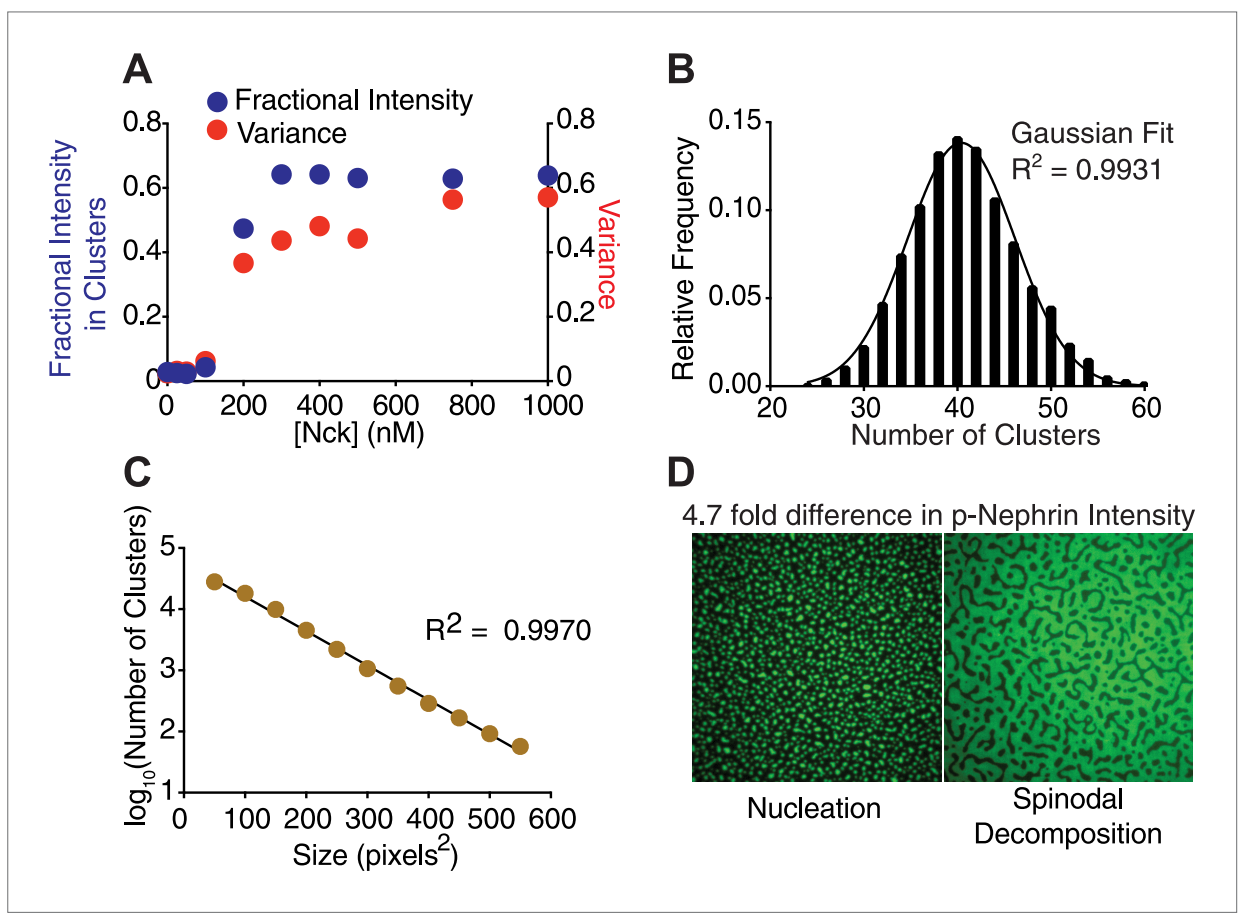

Figure 2. Nephrin clusters are created via a two-dimensional phase-transition. (A) Fractional intensity in clusters (blue symbols, left ordinate) and signal variance (red symbols, right ordinate) of p-Nephrin fluorescence on a DOPC bilayer as a function of Nck concentration for $500 \mathrm{nM} \mathrm{N-WASP}$ and total p-Nephrin density of $\sim 2700 \mathrm{molecules} / \mu \mathrm{m}^{2}$.

(B) Relative frequency with which a given number of clusters are found within 93 randomly selected $56 \times 56 \mu \mathrm{m}$ regions of a bilayer formed using 2500 molecules/ $\mu m^{2}$ Alexa488-labeled p-Nephrin, $1 \mu \mathrm{M}$ Nck, and $1 \mu \mathrm{M}$ N-WASP. (C) Size distribution of clusters formed using 2500 molecules/ $\mu m^{2}$ Alexa488-labeled p-Nephrin, $1 \mu \mathrm{M}$ Nck, and $1 \mu \mathrm{M}$ N-WASP. (D) Puncta formed using $1 \mu \mathrm{M}$ Nck, $1 \mu \mathrm{M} \mathrm{N}$-WASP, and low (left) or 4.7-fold higher (right) density of p-Nephrin. Images were autocontrasted for clarity.

DOI: 10.7554/eLife.04123.006

The following figure supplements are available for figure 2:

Figure supplement 1. Quantitative analysis of the measurement and control of Hiss-p-Nephrin density on supported lipid bilayers.

DOI: 10.7554/eLife.04123.007

Figure supplement 2. Quantification of average p-Nephrin density on the bilayer for every titration point shown in Figure 2A.

DOI: 10.7554/eLife.04123.008

follows a power law (Figure 3-figure supplement 2). At a given time after Nck/N-WASP addition, higher density produces a larger average cluster size and correspondingly a larger fraction of total area covered by the clusters (Figure 3-figure supplement $3 A, B$, respectively), most likely due to the larger degree of coalescence at higher cluster densities. A detailed mechanistic understanding of these behaviors will be goal of future efforts.

We next used fluorescence recovery after photobleaching (FRAP) to examine the dynamics of the three proteins that compose the clusters. In individual experiments, we labeled either p-Nephrin, Nck, or N-WASP with Alexa488 and examined FRAP behavior of the labeled component. Within the clusters, each of the proteins recovers nearly fully in tens to hundreds of seconds (Figure 3B). Thus, even though the clusters themselves are persistent for hours, the individual components exchange with the surroundings on time-scales of seconds to minutes. The recovery profiles can all be fit to a doubleexponential but do not fit to a single-exponential (see 'Materials and methods' for F-test statistics). $\mathrm{N}-$ WASP shows recovery time constants of $\mathrm{T}-\mathrm{fast}=2.6 \mathrm{~s}(37 \%)$ and T-slow $=43 \mathrm{~s}(63 \%)$. Nck recovers with $\mathrm{T}$-fast $=1.6 \mathrm{~s}(49 \%)$ and $\mathrm{T}$-slow $=72 \mathrm{~s}(51 \%)$. $\mathrm{p}$-Nephrin recovers with $\mathrm{T}$-fast $=86 \mathrm{~s}(76 \%)$ and $\mathrm{T}$-slow $=526 \mathrm{~s}(24 \%)$. In the non-clustered regions, $\mathrm{p}$-nephrin recovery can be fit well to a singleexponential, with $\mathrm{T}=31 \mathrm{~s}$, similar to the fast phase in the clusters but appreciably slower than recovery in the absence of Nck/N-WASP, where $\mathrm{T}=1.3 \mathrm{~s}$ (Figure 1-figure supplement 1A). In independent 


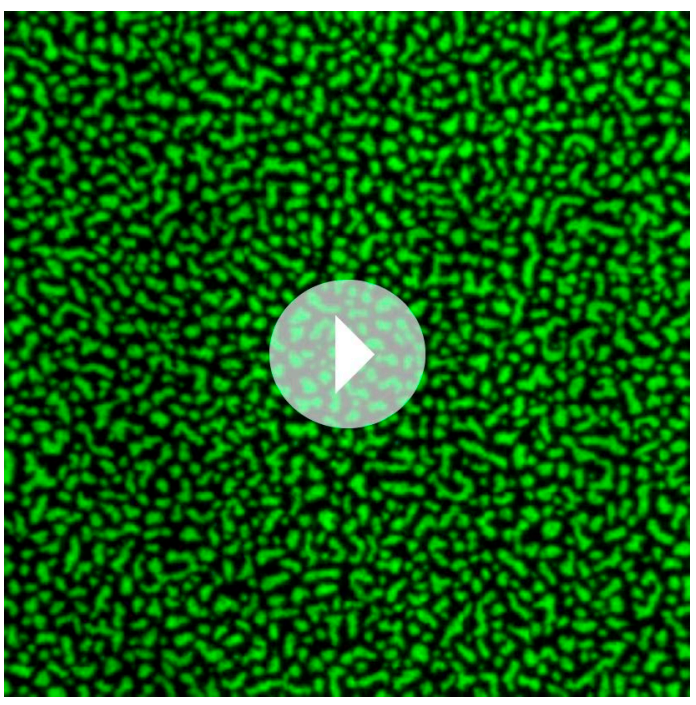

Video 2. Clusters are dynamic. Time-lapse of clusters made from $1 \mu \mathrm{M}$ Nck and $1 \mu \mathrm{M} N$-WASP with $\mathrm{p}$-Nephrin Alexa488 on the membrane. Images were captured every $30 \mathrm{~s}$. In addition to fusion events, the clusters also occasionally undergo fission.

DOI: 10.7554/eLife.04123.009 experiments we found that the dissociation of $\mathrm{p}$-nephrin from the membrane occurs much more slowly than these rates ( $\mathrm{T}=2080 \mathrm{~s}$, Figure 2-figure supplement 1D), indicating that the FRAP recovery of the protein is largely due to two-dimensional diffusion within the bilayer. By contrast, Nck and N-WASP likely recover through a combination of diffusion in the plane of the bilayer as well as binding and dissociation from the membrane. We recognize that the kinetic processes here must represent the convolution of multiple molecular processes, given the complex oligomeric/polymeric nature of the clusters (see below). Nevertheless, the data suggest that both the clustered regions and non-clustered regions contain small assemblies that slow p-nephrin dynamics relative to its free diffusion in the bilayer. The clustered region likely contains additional assemblies that are larger and have greater degrees of crosslinking that appreciably slow dynamics further.

Together, our data show that upon recruitment of Nck and N-WASP, membrane-bound p-nephrin undergoes a sharp thermodynamically controlled phase transition to produce dense dynamic puncta on the membrane.

\section{Phase separation occurs through polymerization of p-nephrin, Nck and N-WASP}

Our previous data suggested that three dimensional phase separation in the p-nephrin/Nck/N-WASP system occurred concomitantly with a sol-gel transition, producing macroscopic non-covalent polymers within the liquid phase boundary. Evidence for polymerization came in part from studies of the dependence of critical concentration and dynamics on the valencies and affinities of the interacting species. To examine whether such polymerization is also occurring in the two-dimensional system, we initially compared the critical concentrations of singly-, doubly-, and triply-phosphorylated nephrin (Nephrin1pY, Nephrin2pY, and p-Nephrin, respectively; see 'Materials and methods' for specific phosphorylation sites). Previous studies showed that the three nephrin pTyr sites have essentially identical affinities for the Nck SH2 domain (Blasutig et al., 2008). Thus, these constructs differ largely in pTyr valency, rather than inherent affinity for Nck. At a membrane density of $1000 \mathrm{molecules} / \mu \mathrm{m}^{2}$ and in the presence of 500 nM N-WASP, p-Nephrin begins to show clusters at 200-300 nM Nck. Under the same conditions, Nephrin2pY and Nephrin1pY do not cluster even at Nck concentrations greater than $10 \mu \mathrm{M}$ (Figure 4A) nor with their own densities increased to 3000 molecules $/ \mu \mathrm{m}^{2}$. If the concentrations of N-WASP and Nck are increased to $2 \mu \mathrm{M}$ and $5 \mu \mathrm{M}$, respectively, Nephrin2pY produces clusters (Figure 4-figure supplement 1). However, even at $5 \mu \mathrm{M} N-W A S P$ and $10 \mu \mathrm{M}$ Nck, Nephrin1pY does not cluster (Figure 4-figure supplement 1). Thus, the valency of nephrin phosphorylation can control the critical concentration for puncta formation, as in the three-dimensional phase separation of this system (Li et al., 2012).

We also performed analogous studies of the SH3 valency of Nck. Since the different SH3 domains of Nck have different affinities for the individual PRM sites in N-WASP (Qiong Wu, unpublished observations), we generated a series of Nck analogs, containing one, two, or three repeats of the second $\mathrm{SH} 3$ domain of the protein plus the natural $\mathrm{SH} 2$ domain $\left[(\mathrm{SH} 3)_{1},(\mathrm{SH} 3)_{2}\right.$, and $(\mathrm{SH} 3)_{3}$, respectively]. The $\mathrm{SH} 3$ domains were separated by the natural linker between the first and second $\mathrm{SH} 3$ domains. At $500 \mathrm{nM} \mathrm{N-WASP}$, the trivalent molecule $(\mathrm{SH} 3)_{3}$ induces clustering at $200 \mathrm{nM}(\mathrm{SH} 3$ module concentration), whereas the di-valent $(\mathrm{SH} 3)_{2}$ and monovalent $(\mathrm{SH} 3)_{1}$ molecules do not cluster even at concentrations above $10 \mu \mathrm{M}$ of the $\mathrm{SH} 3$ module concentrations (Figure 4B). Increasing N-WASP concentration to $5 \mu \mathrm{M}$ and $(\mathrm{SH} 3)_{2}$ concentration to $5 \mu \mathrm{M}$ (SH3 module concentration) produced clusters, whereas clusters were absent even with $5 \mu \mathrm{M} \mathrm{N}$-WASP and $5 \mu \mathrm{M}(\mathrm{SH} 3)_{1}$ 


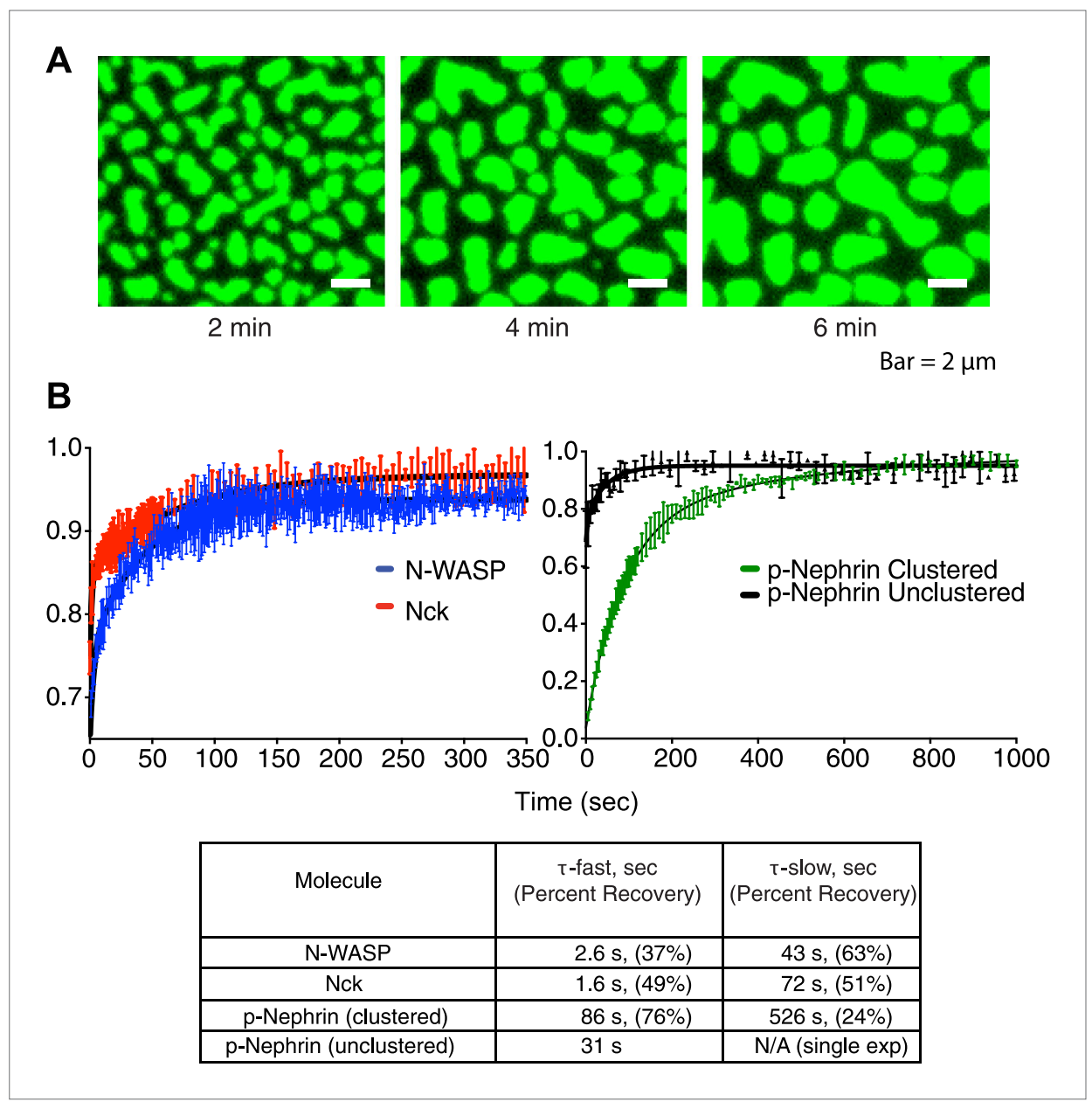

Figure 3. Clusters are dynamic. (A) Time-lapse TIRF imaging of bilayers containing $\sim 3100$ molecules $/ \mu m^{2}$ Alexa488labeled p-Nephrin after addition of $1 \mu \mathrm{M} N \mathrm{Nk}$ and $1 \mu \mathrm{M}$ N-WASP. Images represent time intervals of $2 \mathrm{~min}$ and show coalescence of clusters into larger structures. (B) Fluorescence recovery after photobleaching of Nck and N-WASP in clustered regions (left panel, red and blue, respectively) and p-Nephrin in clustered and unclustered regions (right panel, green and black, respectively). FRAP experiments were performed in separate experiments using Alexa-488 labeled p-Nephrin, Nck, or N-WASP. Lines show bi-exponential fits of the data, except for unclustered $\mathrm{p}$-Nephrin, which was fit using a single-exponential. Bars represent standard deviation from three FRAP experiments on a single bilayer. Bottom table lists the parameters obtained from the fitting. DOI: 10.7554/eLife.04123.010

The following figure supplements are available for figure 3:

Figure supplement 1. Cluster size-distribution analyses at different times suggest exponential behavior at lower densities.

DOI: 10.7554/eLife.04123.011

Figure supplement 2. Cluster size-distribution analyses suggest power law behavior at higher densities. DOI: 10.7554/eLife.04123.012

Figure supplement 3. Average cluster size is dependent on molecular density. DOI: 10.7554/eLife.04123.013

(Figure 4-figure supplement 1). These data demonstrate the strong dependence of clustering on valency of the interacting species.

To determine the effect of SH2-pTyr affinity on the clustering concentrations, we replaced the three pTyr motifs of Nephrin with three repeats of the pTyr motif of the bacterial protein TIR ( $p$-TIR) (Campellone et al., 2002). The binding affinity of the p-Nephrin motif to the SH2 domain of Nck is $370 \mathrm{nM}$, as determined by isothermal titration calorimetry (Figure 5-figure supplement 1). For the $\mathrm{p}$-TIR motif the affinity to the $\mathrm{SH} 2$ domain is $40 \mathrm{nM}$. In the presence of $\mathrm{p}$-TIR, at a density of 


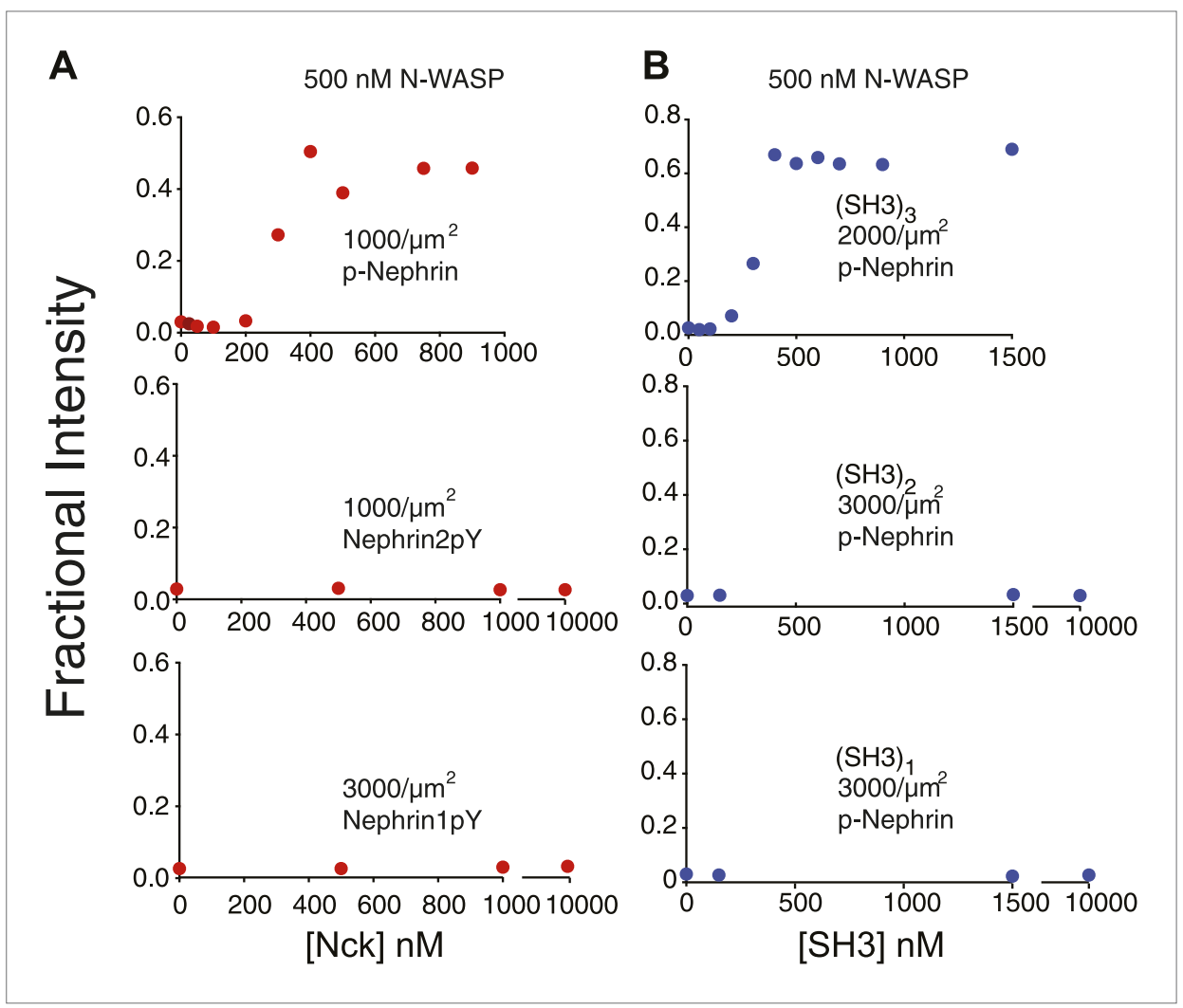

Figure 4. Clustering is dependent upon the valency of the interacting motifs. Plots show fractional intensity of fluorescent Nephrin proteins in clusters as a function of Nck protein concentrations for $500 \mathrm{nM}$ N-WASP. (A) Top, middle, and bottom panels show data for $\mathrm{p}-\mathrm{Nephrin} 3 \mathrm{pY}, 2 \mathrm{pY}$, and 1pY, respectively. For these concentrations of N-WASP and Nck, only Nephrin 3pY shows clustering. At $2 \mu \mathrm{M} N-W A S P, N e p h r i n 2 p Y$ also clusters when Nck is added (Figure 4-figure supplement 1). (B) Top, middle, and bottom panels show data for $\mathrm{p}$-Nephrin plus engineered Nck proteins containing 3, 2, or 1 repeat of the second SH3 domain of Nck. For these concentrations/densities of $\mathrm{N}-\mathrm{WASP} / \mathrm{p}-\mathrm{Nephrin}$, only the $(\mathrm{SH} 3)_{3}$ protein can induce clustering. At $5 \mu \mathrm{M} \mathrm{N}-\mathrm{WASP},(\mathrm{SH} 3)_{3}$ also induces clustering (Figure 4-figure supplement 1). Note that the $\mathrm{x}$-axis is Nck concentration in panel $\mathbf{A}$ but total SH3 domain concentration in panel B.

DOI: 10.7554/eLife.04123.014

The following figure supplement is available for figure 4:

Figure supplement 1. Di-valent molecules are stronger clustering agents than mono-valent molecules. DOI: 10.7554/eLife.04123.015

2000 molecules $/ \mu^{2}{ }^{2}$, the clustering concentration of the trivalent SH3 protein, (SH3) 3 , is $100 \mathrm{nM}$, as opposed to $200 \mathrm{nM}$ for $\mathrm{p}-N e p h r i n$ (Figure 5A). The higher affinity interaction also slows the recovery of Nck, as FRAP data demonstrate (Figure 5B). Fitting to a double-exponential, Nck shows recovery rate constants of $\mathrm{T}$-fast $=6.5 \mathrm{~s}(46 \%)$ and $\mathrm{T}$-slow $=89.5 \mathrm{~s}(54 \%)$ when the clusters of $\mathrm{p}$-TIR/Nck/N-WASP were photobleached. However, Nck shows recovery rates of T-fast $=1.6 \mathrm{~s}(49 \%)$ and $\mathrm{T}$-slow $=73.2 \mathrm{~s}$ (51\%) when the clusters of p-Nephrin/Nck/N-WASP were photobleached. The data would be consistent with T-fast being governed by processes based on dissociation of Nck from pTyr sites on Nephrin/TIR (which are likely slower in the high affinity system) and T-slow being governed by diffusion of large assemblies in the membrane (which are expected to be similar in the two cases). Together, the data show that both the clustering concentrations and the dynamics of the clusters can be affected by molecular affinities, as expected of a crosslinked polymer network.

Additionally when a higher-affinity monovalent pTyr peptide is added in solution, the clusters dissipate. In the presence of clusters made from $1 \mu \mathrm{M}(\mathrm{SH} 3)_{3}, 500 \mathrm{nM} \mathrm{N}-$ WASP and p-nephrin, we added singly phosphorylated TIR peptide (without a His tag) at $10 \mu \mathrm{M}$ concentration (Video 3, Figure 6A). The clusters disappear within minutes after the addition of the monovalent peptide. The dissolution of the clusters occurs sharply, over a time-span of $\sim 2 \mathrm{~min}$, starting $\sim 7 \mathrm{~min}$ after peptide addition (Figure 6B). 


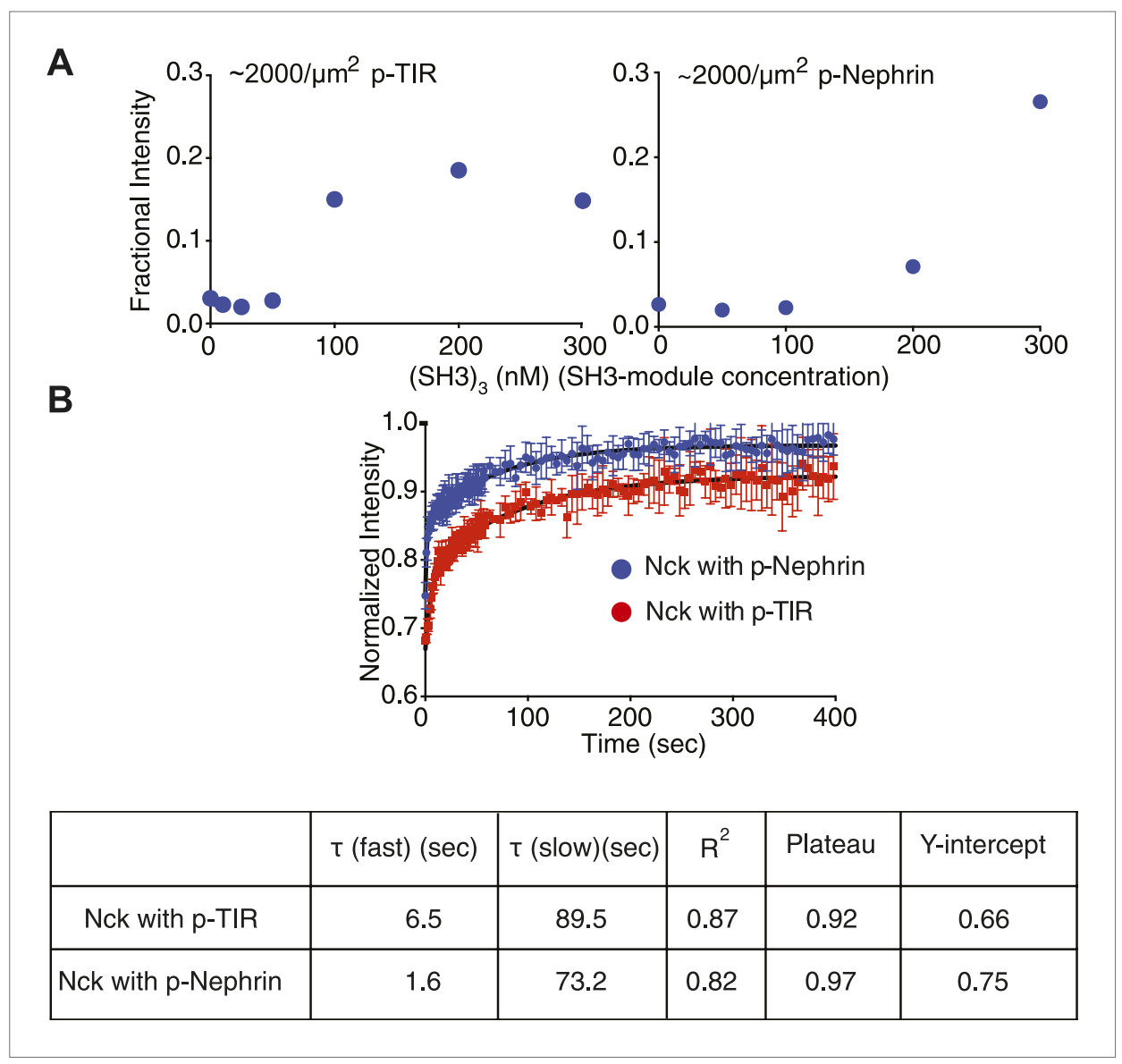

Figure 5. Molecular affinities affect macroscopic clustering. (A) Fractional intensity of fluorescent pTyr proteins in clusters as a function of SH3 (module) concentrations for $500 \mathrm{nM} \mathrm{N-WASP.} \mathrm{Left} \mathrm{and} \mathrm{right} \mathrm{panels} \mathrm{show} \mathrm{data} \mathrm{for} \mathrm{a} \mathrm{p-TIR}$ and $\mathrm{p}$-Nephrin, whose pTyr motifs bind the SH2 domain of Nck with $K_{D}$ values of $40 \mathrm{nM}$ and $370 \mathrm{nM}$, respectively. (B) Fluorescence recovery after photobleaching (FRAP) for Alexa488-labeled Nck in p-Nephrin clusters (blue) and $\mathrm{p}$-TIR clusters (red). Nck recovers more slowly (larger T), can be bleached more strongly (Y-intercept) and recovers to a lower value (plateau) with $\mathrm{p}$-TIR than with $\mathrm{p}$-Nephrin, all indicating slower dynamics in clusters with the higher affinity $\mathrm{SH} 2$ binding partner. The bars represent standard deviation from three FRAP experiments on a single bilayer. DOI: 10.7554/eLife.04123.016

The following figure supplement is available for figure 5 :

Figure supplement 1. Measurement of the affinity of Nck for p-TIR and p-Nephrin.

DOI: 10.7554/eLife.04123.017

When TIR is titrated from $100 \mathrm{nM}$ to $100 \mu \mathrm{M}$, the fractional intensity of the clusters also decreases sharply above $10 \mu \mathrm{M}$ (Figure $6 \mathrm{C}$ ). These data suggest that the disassembly of the clusters (similar to the formation) is also cooperative.

The favorability of higher valency and higher affinity on clustering, as well as the disruption of the clusters by a mono-valent molecule, suggest that as in the three dimensional droplets the two dimensional clusters form through polymerization (a sol-gel transition) of p-Nephrin, Nck and N-WASP.

\section{p-Nephrin/Nck/N-WASP clusters promote Arp2/3 complex-dependent actin assembly}

We next asked whether the p-Nephrin/Nck/N-WASP clusters can direct actin assembly by the Arp2/3 complex at membranes. We added monomeric actin ( $10 \%$ rhodamine labeled) to the solution above preformed clusters in the presence or absence of the Arp $2 / 3$ complex, under conditions that favor actin polymerization. Immediately after addition a small amount of actin, likely monomers, is recruited to the clusters in a relatively uniform fashion (Figure 7-figure supplement 1A). After a lag of 6-15 min 


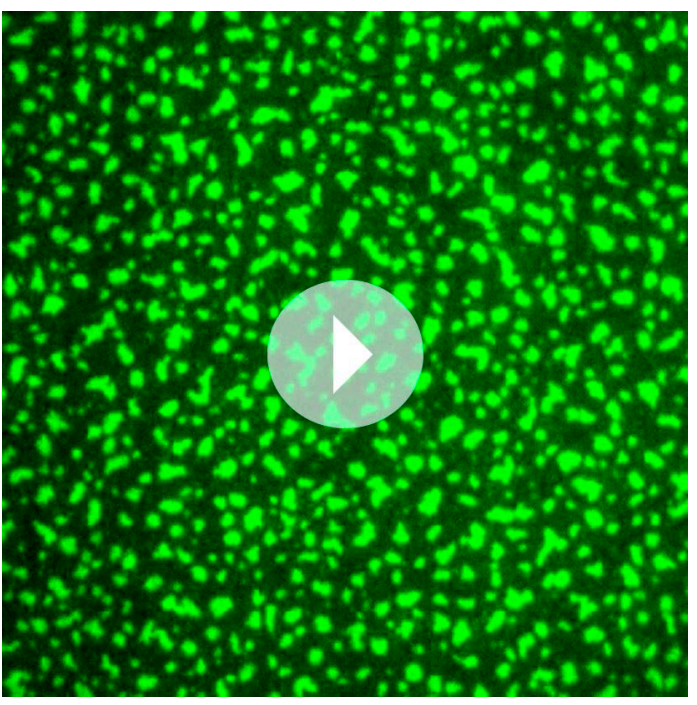

Video 3. Mono-valent peptide dissolves clusters. Addition of $10 \mu \mathrm{M} 1 \mathrm{pY}$-TIR causes the clusters of $1 \mu \mathrm{M}$ $(\mathrm{SH} 3)_{3}$ and $500 \mathrm{nM}$ N-WASP to dissipate. Images were captured every $30 \mathrm{~s}$.

DOI: 10.7554/eLife.04123.018

vior likely reflects strong positive feedback due to activation of the Arp2/3 complex by actin filaments (Machesky et al., 1999).

As the reaction proceeds, the morphology of the Nephrin clusters changes dramatically, without appreciable changes on overall intensity (except the slow decrease due to photobleaching). Actin fluorescence remains coincident with Nephrin throughout this process, indicating that the signaling molecules are reorganized by the assembling filaments. Shortly after the appearance of actin on a cluster, the structure changes from having relatively rounded edges to having many thin hair-like projections from its periphery. These projections coalesce over time to give the puncta star-like morphologies. For reasons we cannot currently explain, between 42 and $45 \mathrm{~min}$, well after all of the clusters have recruited significant actin, there is a dramatic change in cluster morphology, such that the puncta appear to shatter into a large number of short linear structures (Figure 7-figure supplement 2). This change in Nephrin morphology coincides with a sharp increase in the total actin localized to the TIRF field/membrane but no change in total Nephrin fluorescence.

These data demonstrate the $\mathrm{p}$-Nephrin/Nck/N-WASP clusters can effectively promote actin filament assembly through the Arp $2 / 3$ complex (which is presumably recruited to the membrane through binding N-WASP). As the filaments assemble, they cause substantial changes in the morphology of the clusters. This feedback between actin and the signaling proteins that promote its assembly can control the micron-scale morphology of the entire pathway.

\section{Discussion}

\section{Polymerization and concomitant phase separation as a general mechanism to create membrane clusters}

We have shown here that membrane-bound phosphorylated Nephrin can form micron-size clusters through interactions with Nck and N-WASP. The clusters form through a thermodynamic phase transition that is driven by oligomerization/polymerization of the proteins through their modular binding domains. The occurrence of a phase transition is supported by the sharpness with which clusters appear as Nck concentration is increased and the temporal sharpness of cluster disappearance after a monovalent competitor is added. The importance of polymerization/oligomerization is supported by the valency- and affinity-dependence of the critical concentration and also by the dissolution of clusters by a monovalent competitor. The clusters appear to be polymers/oligomers of the three proteins, as evidenced by the dependence of FRAP rate on the affinity of the Nck SH2 domain for the pTyr sites on 


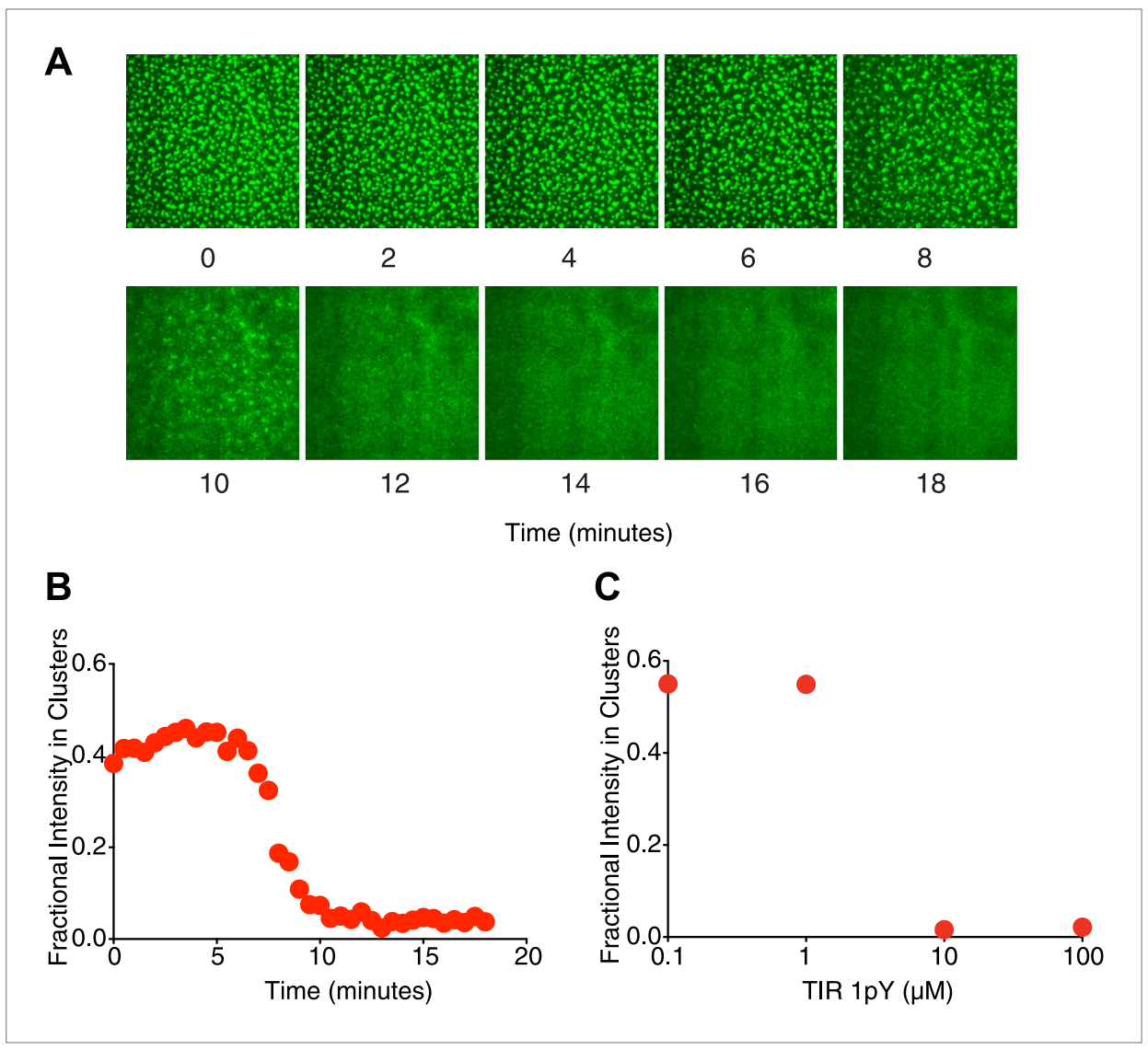

Figure 6. Mono-valent pTyr peptide can eliminate clusters. (A) Time course following addition of $10 \mu \mathrm{M}$ of a monovalent pTyr peptide derived from TIR (with $\mathrm{K}_{\mathrm{D}}$ of $40 \mathrm{nM}$ for the Nck SH2 domain) to clusters formed from $\mathrm{p}-$ Nephrin /(SH3) 3 /N-WASP. (B) Time course of the fractional p-Nephrin intensity in clusters after addition of the TIR peptide. (C) Equilibrium fractional intensity of the $\mathrm{p}$-Nephrin clusters as a function of $\mathrm{p}$-TIR peptide concentration, performed in the presence of $1 \mu \mathrm{M}(\mathrm{SH} 3)_{3}$ and $500 \mathrm{nM}$ N-WASP. DOI: 10.7554/eLife.04123.019

Nephrin. The clusters assemble actin through the Arp2/3 complex and can themselves be dynamically remodeled by the resultant filament network. Our work demonstrates that, as in three-dimensional systems, multivalent polymerization and phase separation can control micron-scale spatial organization (and likely biochemical activity) of signaling pathways.

This process may contribute generally to the organization of signaling receptors. The cytoplasmic tails of many receptors are rapidly phosphorylated on multiple tyrosine residues upon stimulation by extracellular ligands (Roche et al., 1996; Hunter, 2000; Palmer et al., 2002; Schlessinger, 2000; Houtman et al., 2006; Kaushansky et al., 2008; Wagner et al., 2013). This often occurs concomitant with concentration of the receptors into micron-sized puncta (Douglass and Vale, 2005; Salaita et al., 2010). Where examined, these puncta persist over many minutes, but exchange molecules in seconds with the surroundings, similar to the $\mathrm{p}-\mathrm{Nephrin/Nck/N-WASP}$ puncta we have generated here. Further, many of these receptors have been shown, through combinations of biochemistry and genetics, to use the pTyr modifications to engage signaling networks composed of proteins with multiple modular binding domains, often (but not exclusively) combinations of SH2 domains, SH3 domains, PRMs, and additional pTyr sites. Examples of processes controlled by such pathways include T cell activation (Lee et al., 2003; Dustin et al., 2010), invadopodia formation (Oser et al., 2010; Bergman et al., 2014), myoblast fusion (Abmayr and Pavlath, 2012), neurite self-avoidance (Chen and Maniatis, 2013), and cell-matrix interactions through focal adhesions (Hoffmann et al., 2014). The molecules that control these processes have the capacity to function analogous to the Nephrin/Nck/N-WASP system studied here. We hypothesize that coupled polymerization and phase separation may contribute to the formation of macroscopic puncta in these systems and others that are composed similarly. 


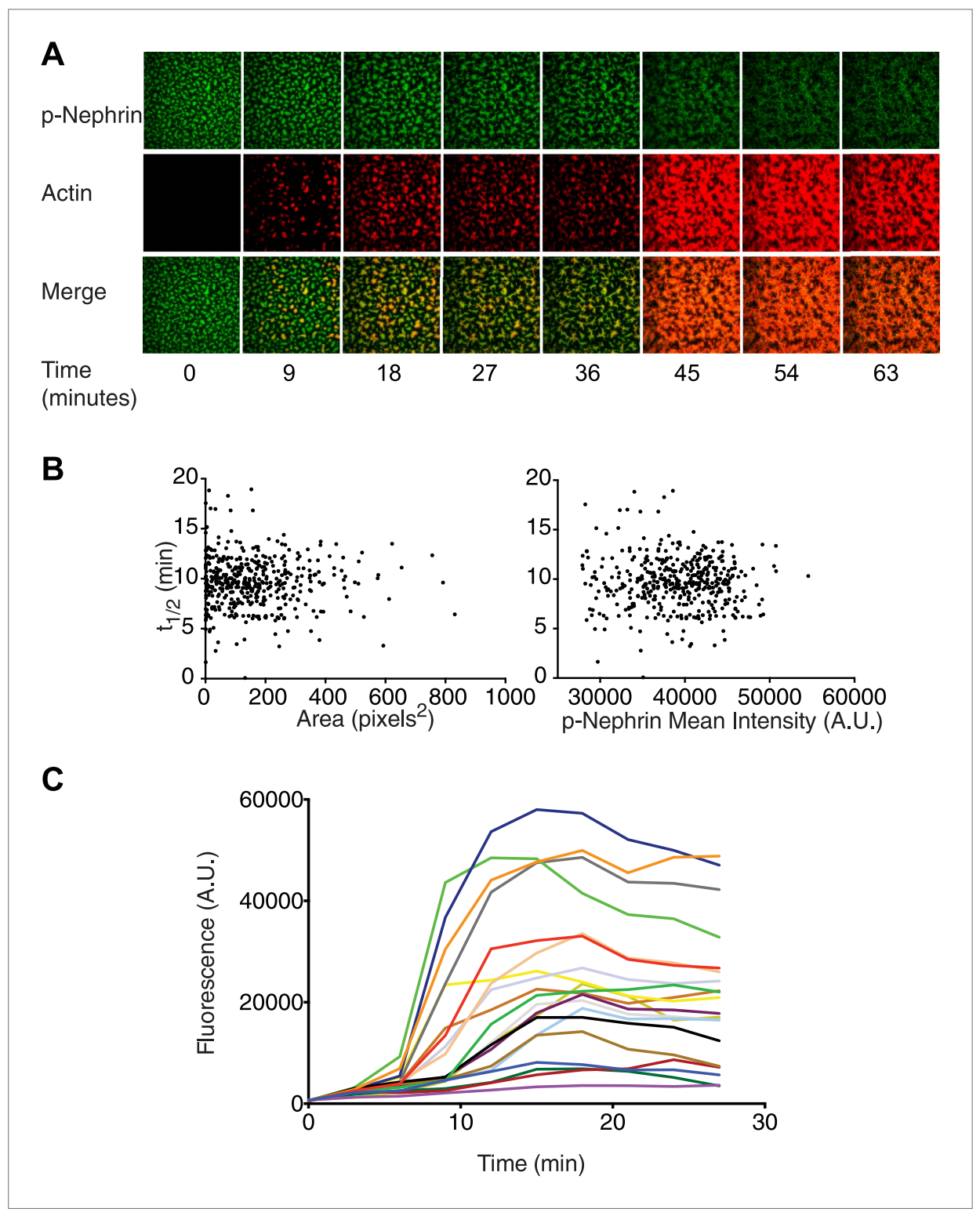

Figure 7. Actin assembles specifically on p-Nephrin/Nck/N-WASP clusters. (A) Alexa488-labeled p-Nephrin $\left(2200\right.$ molecules $\left./ \mu m^{2}\right)$ was clustered by addition of $2 \mu \mathrm{M} \mathrm{N}$-WASP and $1 \mu \mathrm{M}$ Nck. Images show time course of $\mathrm{p}-$ Nephrin (top row), actin (middle row) and merge (bottom row) after addition of $10 \mathrm{nM}$ Arp2/3 complex and $1 \mu \mathrm{M}$ actin (10\% rhodamine labeled). (B) Half-times of actin assembly as a function of surface area (left-panel) and $\mathrm{p}$-Nephrin intensity (right-panel) in individual clusters. Half-times were calculated using the data for the first 27 min of the time-lapse. (C) Fluorescence of rhodamine-actin on individual clusters as a function of time for 20 representative clusters. Individual curves represent average intensity across an individual cluster.

DOI: 10.7554/eLife.04123.020

The following figure supplements are available for figure 7:

Figure supplement 1. Actin localizes to and assembles on the clusters in an Arp2/3 dependent manner. DOI: 10.7554/eLife.04123.021

Figure supplement 2. Actin assembly reorganizes $p-N e p h r i n$ clusters.

DOI: 10.7554/eLife.04123.022

We note that polymerization does not strictly require multivalency at the level of an individual receptor tail. At high densities, a receptor containing a single motif behaves effectively in multivalent fashion and can then cluster through interactions with multivalent ligands. For example, proteins with multiple PDZ domains interact with voltage-gated Kv1.4 channels, which are found in clusters at the 
cell-surface (Burke et al., 1999). Further, membrane receptors are often oligomeric in nature. For example, EGF receptors have been reported to form pre-formed oligomers in the absence of ligand (Clayton et al., 2008), effectively increasing the valency of their cytoplasmic tails. Thus, there are a variety of ways that the basic concept of multivalent polymerization and phase separation could be manifested in specific signaling systems.

This behavior appears to be particularly prominent in actin regulatory pathways. These often contain the adaptor proteins Nck or Crk/CrkL, linked upstream to pTyr-containing proteins and downstream to proline-rich proteins including members of the WASP family (Buday et al., 2002; Antoku et al., 2008; Noy et al., 2012; Chaki and Rivera, 2013; Kaipa et al., 2013). In this regard, it is notable that over half of the 29 known ligands of the Nck SH2 domain contain two or more (up to 16 in p130 CAS) predicted and/or demonstrated Nck binding sites (Lettau et al., 2009). Further, almost all WASP proteins have large proline-rich regions with multiple SH3-binding PRMs (Padrick and Rosen, 2010). The only exception is WASH, which has a small proline-rich region. However, WASH is constitutively associated with the Fam21 protein, which has a large disordered tail that contains 21 so-called LFa peptide motifs that can bind the membrane-associated retromer complex (Derivery et al., 2009; Gomez and Billadeau, 2009; Jia et al., 2010, 2012). Thus WASH may have a conceptually similar but molecularly distinct mechanism of assembling into large structures. This general behavior suggests that clustering may play an important role in spatial and temporal control of actin dynamics. Consistent with this idea, several groups have demonstrated that increased density of WASP proteins corresponds to increased activity towards the Arp2/3 complex. Pantaloni and colleagues have shown that the rate of actin-based motility of N-WASP-coated beads increases non-linearly with increasing WASP density (Wiesner et al., 2003). Similarly, Ditlev et al. have shown through modeling and cell-based experiments that actin assembly activity scales with the square of N-WASP density at the plasma membrane (Ditlev et al., 2012). Finally, Padrick et al. showed that a natural consequence of the 2:1 stoichiometry of the WASP:Arp2/3 complex during filament nucleation is that actin assembly activity should increase with the size of WASP clusters and thus the density of WASP at membranes (Padrick et al., 2008). These observations, together with our data here, suggest that clustering of receptors and their proximal adaptors may provide a mechanism of concentrating WASP proteins into high-density puncta and thus increasing their activation of the Arp2/3 complex, providing local bursts of actin filament assembly.

The mechanism we have described is not exclusive of, and in fact is expected to act cooperatively with, many other mechanisms that have been proposed to explain receptor clustering. Interactions between extracellular domains, as proposed for cadherins and Eph receptors (Himanen et al., 2007; Wu et al., 2011; Seiradake et al., 2013), will be thermodynamically coupled to assembly of intracellular oligomers/polymers. Similarly, interactions of receptor transmembrane regions with specific lipids, which can promote concentration of receptors into nano-domains enriched in those lipids, should also be thermodynamically coupled to the clustering of receptor cytoplasmic tails (Lingwood and Simons, 2010). Further, ATP-dependent clustering of the cortical acto-myosin system, which promotes oligomerization of GPI-anchored proteins (Sharma et al., 2004; Goswami et al., 2008), could also promote assembly of a phase separated multivalent network if any components of that network can bind to the cytoskeleton. In this case, the dynamic rearrangements of the acto-myosin system could also control the properties of the signaling clusters (e.g., cluster size and/or lifetime of clusters) and maintain them away from equilibrium. It is important to note that while weak interactions between extracellular domains or between transmembrane regions and lipids or between receptors and the cytoskeleton may not on their own produce significant oligomerization of receptors, these energies could have substantial effects when combined with energies of clustering. Phrased differently, these other interactions could have strong effects on the critical concentrations (or the degree of receptor phosphorylation) needed for phase separation/clustering through adaptor-based intracellular interactions. For any particular system, or for a single system under different conditions, these various mechanisms are likely to be used to different degrees to promote the organization of receptors into macroscopic structures.

\section{Functional implications of clustering through multivalent phase separation}

The ability of membrane receptors to cluster through multivalent phase separation could have a number of functional implications in cells. The process will generate a sharp switch between different states, which will depend on the concentrations of at least two (and possibly several) species, as well 
as the degree of receptor phosphorylation in pTyr-dependent cases. Thus, the switch could be tightly controlled, either through relatively slow changes in protein concentration or more rapidly through changes in receptor phosphorylation or oligomerization by extracellular ligands. The phase-separated state will have different density, composition, and dynamics from the surrounding regions of the membrane, each of which could have functional consequences. In the case of actin regulatory systems, we and others have shown that because WASP proteins bind (and activate) Arp2/3 complex in 2:1 fashion, increasing density of WASP proteins leads to non-linear increases in actin assembly activity (Padrick et al., 2008; Ditlev et al., 2012). Thus, clustering should provide not only spatial organization of the actin filament network (decreasing spatial noise [Grecco et al., 2011]) but also increased biochemical signaling activity. This should be true for any signaling system that requires multiple simultaneous or sequential events to generate downstream outputs. The enhancement due to clustering would be particularly strong for systems with positive feedback, as in Arp2/3 complex-actin pathways. In addition to the polymer components themselves, other proteins and lipids could be concentrated into or excluded from the phase-separated structure. This partitioning could be dictated by both specific interactions (e.g., a monovalent SH3 protein could be recruited to the $\mathrm{p}-\mathrm{Nephrin/Nck/N-WASP}$ clusters by binding the PRMs of N-WASP) as well as non-specific electrostatic and/or hydrophobic interactions with the polymer matrix. The collection of these molecules would then produce a distinct biochemical environment from the surrounding regions, favoring or disfavoring certain reactions or afford specificity to signaling pathways. Since the clusters are temporally stable but readily exchange molecules with the surroundings, they could potentially act as sites of enzymatic modification and release. Finally, the structural and dynamic features of the polymer matrix could also influence the rates and/or specificities of reactions that occur within the clusters.

\section{Nephrin oligomerization as a mechanism to organize the slit diaphragm}

Recent data have shown that Nephrin is constitutively phosphorylated in the slit diaphragm between podocytes of the kidney (Jones et al., 2009; New et al., 2013). Previous data showed that the loss of Nck disrupts the filtration capacity of the diaphragm, concomitant with the loss of cortical actin filaments (Jones et al., 2006). These observations suggest that the pathway from p-Nephrin to actin, and by inference the polymeric network we have described here, is important in maintaining the slit diaphragm. The extracellular portion of Nephrin is composed of multiple IgG domains and FNIII domains. These have been suggested to self-associate, both in trans across the slit diaphragm and in cis within individual cells (Gerke et al., 2003). The latter should promote polymerization and phase separation of the actin pathway components. Thus, this system may be a case where interactions on both sides of the plasma membrane act cooperatively to produce a polymeric structure with both extracellular functions (the filtration barrier) and intracellular functions (signaling to actin).

\section{Conclusion}

In summary, we have shown that interactions between multivalent proteins at membranes can lead to concomitant polymerization and phase separation, generating micron-size clusters. Although only demonstrated here for the p-Nephrin/Nck/N-WASP system, the analogous construction of many signaling pathways suggests that this behavior could be quite general, and relevant to many biological processes. Polymerization and phase separation at membranes could impart spatial organization on these pathways and afford them strongly non-linear activities. Further work in vitro and in vivo will be necessary to determine the extent to which these effects are important in specific biological processes.

\section{Materials and methods}

\section{Protein expression and purification, phosphorylation of nephrin}

Information on different constructs is provided in Table 1. Maltose binding protein (MBP)-tagged $\mathrm{His}_{8-}$ Nephrin and its mutants were expressed in BL21(DE3)T1R cells at $18^{\circ} \mathrm{C}$ through overnight induction with $1 \mathrm{mM}$ IPTG. Cells were collected by centrifugation and lysed by cell disruption (Emulsiflex-C5, Avestin, Ottowa, ON, Canada) in $20 \mathrm{mM}$ Tris, pH 8, $20 \mathrm{mM}$ imidazole, $150 \mathrm{mM} \mathrm{NaCl}, 5 \mathrm{mM} \mathrm{BME}$, $0.01 \%$ NP-40, $10 \%$ glycerol, $1 \mathrm{mM}$ PMSF, $1 \mu \mathrm{g} / \mathrm{ml}$ antipain, $1 \mathrm{mM}$ benzamidine and $1 \mu \mathrm{g} / \mathrm{ml}$ leupeptin. The cleared lysate was applied to Ni-NTA agarose (Qiagen, Venlo, Netherlands), washed with the lysis buffer containing $300 \mathrm{mM} \mathrm{NaCl}$ and $50 \mathrm{mM}$ imidazole, and eluted with the same buffer but containing $150 \mathrm{mM} \mathrm{NaCl}$ and $300 \mathrm{mM}$ imidazole. The MBP was removed with TEV protease treatment at $4^{\circ} \mathrm{C}$ for $16 \mathrm{hr}$ or at room-temperature for $2 \mathrm{hr}$. The protein was further purified using a Source $15 \mathrm{Q}$ column 
Table 1. Information on the protein constructs used in this study

\begin{tabular}{|c|c|c|}
\hline Proteins & Sequence information & Notes \\
\hline Nck & $\begin{array}{l}\text { GHMAEEWWVAKFDYVAQQEQELD } \\
\text { IKKNERLWLLDDSKSWWRVRNSMNK } \\
\text { TGFVPSNYVERKNSARKASIVKNLK } \\
\text { DTLGIGKVKRKPSVPDSASPADDSF } \\
\text { VDPGERLYDLNMPAYVKFNYMAERED } \\
\text { ELSLIKGTKVIVMEKCSDGWWRGSYN } \\
\text { GOVGWFPSNYVTEEGDSPLGDHVGSL } \\
\text { SEKLAAVVNNLNTGOVLHVVALYPFS } \\
\text { SSNDEELNFEKGDVMDVIEKPENDPEW } \\
\text { WKCRKINGMVGLVPKNYVTVMONNPLT } \\
\text { SGLEPSPPOCDYIRPSLTGKFAGNPWY } \\
\text { YGKVTRHQAEMALNERGHEGDFLIRDS } \\
\text { ESSPNDFSVSLKAQGKNKHFKVQLKET } \\
\text { VYCIGQRKFSTMEELVEHYKKAPIFTS } \\
\text { EQGEKLYLVKHLS }\end{array}$ & Human, WT, residues $1-377$ \\
\hline N-WASP BPVCA & $\begin{array}{l}\text { GSEFKEKKKGKAKKKRAPPPPPPSRGG } \\
\text { PPPPPPPPHSSGPPPPPARGRGAPPPP } \\
\text { PSRAPTAAPPPPPPSRPGVWPPPPPNR } \\
\text { MYPHPPPALPSSAPSGPPPPPPLSMAGS } \\
\text { TAPPPPPPPPPPPGPPPPPGLPSDGDHQ } \\
\text { VPASSGNKAALLDQIREGAQLKKVQNS } \\
\text { RPVSCSGRDALLDQIRQGIOLKSVSDGQE } \\
\text { STPPTPAPTSGIVGALMEVMQKRSKAIHS } \\
\text { SDEDEDDDDEEDFEDDDEWED }\end{array}$ & $\begin{array}{l}\text { Rat, residues 183-193 } \\
\text { fused to } 273-501\end{array}$ \\
\hline Nck (cysteine-modified) & $\begin{array}{l}\text { GHMCMAEEVWVAKFDYVAQQEQELDIKK } \\
\text { NERLWLLDDSKSWWRVRNSMNKTGFVPSNY } \\
\text { VERKNSARKASIVKNLKDTLGIGKVKRKPS } \\
\text { VPDSASPADDSFVDPGERLYDLNMPAYVKF } \\
\text { NYMAEREDELSLIKGTKVIVMEKSSDGWWR } \\
\text { GSYNGQVGWFPSNYVTEEGDSPLGDHVGSL } \\
\text { SEKLAAVVNNLNTGQVLHVVQALYPFSSSND } \\
\text { EELNFEKGDVMDVIEKPENDPEWWKARKING } \\
\text { MVGLVPKNYVTVMQNNPLTSGLEPSPPQSDY } \\
\text { IRPSLTGKFAGNPWYYGKVTRHQAEMALNER } \\
\text { GHEGDFLIRDSESSPNDFSVSLKAQGKNKHF } \\
\text { KVQLKETVYSIGQRKFSTMEELVEHYKKAPIF } \\
\text { TSEQGEKLYLVKHLS }\end{array}$ & $\begin{array}{l}\text { Human, residues 1-377, } \\
\text { with mutations: C139S, } \\
\text { C232A, C266S, C340S }\end{array}$ \\
\hline Nephrin3Y & $\begin{array}{l}\text { GGSLEHHHHHHHHGGSCGGSGGSGGSGG } \\
\text { SHLYDEVERTFPPSGAWGPLYDEVQMGPW } \\
\text { DLHWPEDTFODPRGIYDQVAGD }\end{array}$ & $\begin{array}{l}\text { Human, residues } 1174-1223, \\
\text { with mutations: Y1183F, Y1210F }\end{array}$ \\
\hline Nephrin2Y & $\begin{array}{l}\text { GGSLEHHHHHHHHGGSCGGSGGSGGSGGS } \\
\text { HLFDEVERTFPPSGAWGPLYDEVOMGPWD } \\
\text { LHWPEDTFODPRGIYDQVAGD }\end{array}$ & $\begin{array}{l}\text { Human, residues } 1174-1223 \text {, } \\
\text { with mutations: Y1176F, Y1183F, } \\
\text { Y1210F }\end{array}$ \\
\hline Nephrin1Y & $\begin{array}{l}\text { GGSLEHHHHHHHHGGSCGGSGGSGGSGGSHL } \\
\text { FDEVERTFPPSGAWGPLYDEVOMGPWDLHWP } \\
\text { EDTFQDPRGIFDQVAGD }\end{array}$ & $\begin{array}{l}\text { Human, residues 1174-1223, } \\
\text { with mutations: Y1176F, Y1183F, } \\
\text { Y1210F, Y1217F }\end{array}$ \\
\hline TIR3Y & $\begin{array}{l}\text { GGSLEHHHHHHHHGGSCGGSGGSGGSGGSHM } \\
\text { HIYDEVAADPPPSGAWGHIYDEVAADPWD } \\
\underline{\text { LHWPEDTFQDPRHIYDEVAADP }}\end{array}$ & $\begin{array}{l}\text { Human Nephrin, with pTyr sites } \\
\text { replaced by those in EPEC Tir } \\
\text { protein (underlined) }\end{array}$ \\
\hline$(\mathrm{SH} 3)_{3}$ & $\begin{array}{l}\text { GHMPAYVKFNYMAEREDELSLIKGTKVIVME } \\
\text { KSSDGWWRGSYNGOVGWFPSNYVTEEGDSPL } \\
\text { SARKASIVKNLKDTLGIGKVKRKPSVPSA } \\
\text { SPADDSFVDGERLYDLNMPAYVKNYM } \\
\text { AEREDELSLIKGTKVIVMEKSSDGWWRGSYNGQV } \\
\text { GWFPSNYVTEEGDSPLSARKASIVKNLK } \\
\text { DTLGIGKVKRKPSVPDSASPADDSFVDPGERLY } \\
\text { DLNMPAYVKFNYMAEREDELSLIKGTKV } \\
\text { IVMEKSSDGWWRGSYGOVGWFPNYVTEEG } \\
\text { DSPLNNPLTSGLEPPPQCDYIRPSLTGKFAG } \\
\text { NPWYYGKVTRHOAEMALNERGHEGDFLIRDS } \\
\text { ESSPNDFSVSLKAOGKNKHFKVOLKETVYCI } \\
\text { GQRKFSTMEELVEYKKAPIFTSEQG } \\
\text { EKLYLVKHLS }\end{array}$ & $\begin{array}{l}\text { Human, three repeats of the } \\
\text { second Nck } \mathrm{SH} 3 \text { domain, plus } \\
\text { the Nck } \mathrm{SH} 2 \text { domain }\end{array}$ \\
\hline
\end{tabular}

Table 1. Continued on next page 
Table 1. Continued

\begin{tabular}{|c|c|c|}
\hline Proteins & Sequence information & Notes \\
\hline$(\mathrm{SH} 3)_{2}$ & $\begin{array}{l}\text { GHMPAYVKFNYMAEREDELSLIKGTKV } \\
\text { IVMEKSSDGWWRGSYNGQVGWFPSNYVTEEGD } \\
\text { SPLSARKASIVKNLKDTLGIGKVKRKPSPDSASPADD } \\
\text { SFVDPGERLYDLNMPAYVKFNYMAEREDELSL } \\
\text { IKGTKVIVMEKSSDGWWRGSYNGQVGWFPN } \\
\text { YVTEEGDSPLNNPLTSGLESPPOCDYIRPSLT } \\
\text { GKFAGNPWYYGKVTRHQAEMALNERGHEGDF } \\
\text { LIRDSESSPNDFSVSLKAOGKNKHFKVOLKETVYCIG } \\
\text { ORKFSTMEELVHYKKAPIFTSEQGEKLYLVHLS }\end{array}$ & $\begin{array}{l}\text { Human, two repeats of the } \\
\text { second Nck } \mathrm{SH} 3 \text { domain, plus } \\
\text { the Nck } \mathrm{SH} 2 \text { domain }\end{array}$ \\
\hline$(\mathrm{SH} 3)_{1}$ & $\begin{array}{l}\text { GHMPAYVKFNYMAEREDELSLIKGTKVIVME } \\
\text { KSSDGWWRGSYNGQVGWFPSNYVTEEGDSPL } \\
\text { NNPLTSGLEPSPPQCDYIRPSLTGKFAGNPWYY } \\
\text { GKVTRHQAEMALNERGHEGDFLIRDSESSPNDF } \\
\text { SVSLKAQGKNKHFKVQLKETVYCIGQRKFSTMEEL } \\
\text { VEHYKKAPIFTSEQGEKLYLVKHLS }\end{array}$ & $\begin{array}{l}\text { Human, one repeat of the } \\
\text { second Nck } \mathrm{SH} 3 \text { domain, plus } \\
\text { the Nck } \mathrm{SH} 2 \text { domain }\end{array}$ \\
\hline TIR-1pY & EEHIpYDEVAADPGGSWGGSC & $\begin{array}{l}\text { N-terminal rhodamine labeled } \\
\text { single pTyr motif from EPEC Tir } \\
\text { protein }\end{array}$ \\
\hline Lck & $\begin{array}{l}\text { ANSLEPEPWFFKNLSRKDAERQLLAPGNT } \\
\text { HGSFLIRESESTAGSFSLSVRDFDQNQGEW } \\
\text { KHYKIRNLDNGGFYISPRITFPGLHDLVRHT } \\
\text { NASDGLCTKLSRPCQTOKPOKPWWEDEWEVPRE } \\
\text { TLKLVERLGAGQFGEWWMGYYNGHTKVAVKSLKO } \\
\text { GSMSPDAFLAEANLMKQLQHPRLVRLYAWTQEP } \\
\text { IYIITEYMENGSLVDFLKTPSGIKLNVNKLL } \\
\text { DMAAQIAEGMAFIEEQNYIHRDLRAANILVS } \\
\text { DTLSCKIADFGLARLIEDNEYTAREGAKF } \\
\text { PIKWTAPEAINYGTFTIKSDVWSFGILLT } \\
\text { EIVTHGRIPYPGMTNPEVIQNLERGYRMVRP } \\
\text { DNCPEELYHLMMLCWKERPEDRPTFDYLRSVL } \\
\text { DDFFTATEGQFOPOP }\end{array}$ & Human, 119-509, Y505F \\
\hline
\end{tabular}

DOI: 10.7554/eLife.04123.023

(GE Healthcare, Pittsburgh, PA), evolved with a gradient of $150 \rightarrow 300 \mathrm{mM} \mathrm{NaCl}$ in $20 \mathrm{mM}$ imidazole, $\mathrm{pH} 8,1 \mathrm{mM}$ EDTA, and $2 \mathrm{mM}$ DTT, followed by an SD200 column (GE Healthcare) run in $25 \mathrm{mM}$ Hepes, $\mathrm{pH}$ 7.5, $150 \mathrm{mM} \mathrm{NaCl}, 1 \mathrm{mM} \mathrm{MgCl}$, and $2 \mathrm{mM} \beta M E$. Fractions containing His ${ }_{8}$ Nephrin were concentrated using an Amicon Ultra $3 \mathrm{~K}$ concentrator (Millipore, Billerica, MA) and flash frozen in aliquots at $-80^{\circ} \mathrm{C}$.

Nephrin proteins were phosphorylated at $30^{\circ} \mathrm{C}$ with $20 \mathrm{nM}$ Lck kinase overnight or with $500 \mathrm{nM} \mathrm{Lck}$ for $1 \mathrm{hr}$. The phosphorylation reaction was quenched with $10 \mathrm{mM}$ EDTA. Kinase and incompletely phosphorylated Nephrin were removed using a source $15 \mathrm{Q}$ column evolved with a gradient of $150 \rightarrow 250 \mathrm{mM} \mathrm{NaCl}$ in $25 \mathrm{mM}$ Hepes, pH 7, and $2 \mathrm{mM} \mathrm{\beta ME}$. The phosphorylated product was further purified using an SD200 column (GE Healthcare) and labeled at its single cysteine residue with maleimide-Alexa 488 fluorophore (Invitrogen, Carlsbad, CA). The labeled protein was separated from unreacted fluorophore using a Source $15 \mathrm{Q}$ column and a Hi-trap desalting column (GE Healthcare). Phosphorylation at one, two, or three sites, for Nephrin1Y, Nephrin2Y, or Nephrin3Y (see Table 1), respectively, was confirmed using mass-spectrometry.

GST-Nck and $\mathrm{His}_{6}-\mathrm{N}-$ WASP were expressed in BL21(DE3)T1R cells at $18^{\circ} \mathrm{C}$ through overnight induction with $1 \mathrm{mM}$ IPTG. Cells expressing GST-Nck were collected by centrifugation and lysed by sonication in $20 \mathrm{mM}$ Tris, pH 8, $200 \mathrm{mM} \mathrm{NaCl}, 1 \mathrm{mM}$ EDTA, $1 \mathrm{mM}$ DTT, $1 \mathrm{mM} \mathrm{PMSF}, 1$ rg/ml antipain, $1 \mathrm{mM}$ benzamidine, $1 \mu \mathrm{g} / \mathrm{ml}$ leupeptin, and $1 \mu \mathrm{g} / \mathrm{ml}$ pepstatin. The cleared lysate was applied to glutathione sepharose beads (GE) and washed with 10 column volumes of $200 \mathrm{mM} \mathrm{NaCl}, 20 \mathrm{mM}$ Tris, pH 8, $1 \mathrm{mM}$ DTT, and $1 \mathrm{mM}$ EDTA. The GST tag was removed with TEV protease treatment on the beads at $4^{\circ} \mathrm{C}$ for $16 \mathrm{hr}$ or at room-temperature for $2 \mathrm{hr}$. Cleaved Nck was collected by 20 column washes with $20 \mathrm{mM}$ imidazole, $\mathrm{pH} 7$, and $1 \mathrm{mM}$ DTT and applied to a Source $15 \mathrm{Q}$ column using a gradient of $0 \rightarrow 200 \mathrm{mM}$ $\mathrm{NaCl}$ in $20 \mathrm{mM}$ imidazole, pH 7, 1 mM DTT. Fractions containing Nck were pooled, concentrated using an Amicon Ultra $30 \mathrm{~K}$ concentrator (Millipore), and passed through a Source $15 \mathrm{~S}$ column (GE), using a gradient of $0 \rightarrow 200 \mathrm{mM} \mathrm{NaCl}$ in $20 \mathrm{mM}$ imidazole, pH 7, $1 \mathrm{mM}$ DTT. Fractions containing Nck were concentrated and run through an SD75 column (GE). Pooled fractions were concentrated and flash-frozen 
in $25 \mathrm{mM}$ Hepes, $\mathrm{pH} 7.5,150 \mathrm{mM} \mathrm{NaCl}$, and $1 \mathrm{mM} \mathrm{\beta ME}$. The $(\mathrm{SH} 3)_{1},(\mathrm{SH} 3)_{2}$, and $(\mathrm{SH} 3)_{3}$ proteins were purified in the same way but excluding the Source $15 \mathrm{~S}$ column.

$\mathrm{His}_{6}-\mathrm{N}-\mathrm{WASP}$ expressing cells were collected by centrifugation and lysed by cell disruption (Emulsiflex-C5, Avestin) in $20 \mathrm{mM}$ imidazole, pH 7, $300 \mathrm{mM} \mathrm{KCl}, 5 \mathrm{mM}$ ßME, 0.01\% NP-40, 1 mM PMSF, $1 \mu \mathrm{g} / \mathrm{ml}$ antipain, $1 \mathrm{mM}$ benzamidine, and $1 \mu \mathrm{g} / \mathrm{ml}$ leupeptin. The cleared lysate was applied to Ni-NTA agarose (Qiagen), washed with $300 \mathrm{mM} \mathrm{KCl}, 50 \mathrm{mM}$ imidazole, $\mathrm{pH} \mathrm{7,5} \mathrm{mM} \beta M E$, and eluted with $100 \mathrm{mM} \mathrm{KCl}, 300 \mathrm{mM}$ imidazole, $\mathrm{pH}$ 7, and $5 \mathrm{mM} \beta \mathrm{MME}$. The elute was further purified over a Source $15 \mathrm{Q}$ column using a gradient of $250 \rightarrow 450 \mathrm{mM} \mathrm{NaCl}$ in $20 \mathrm{mM}$ imidazole, $\mathrm{pH} \mathrm{7}$, and $1 \mathrm{mM}$ DTT. The His 6 -tag was removed by TEV protease at $4^{\circ} \mathrm{C}$ for $16 \mathrm{hr}$ or at room-temperature for $2 \mathrm{hr}$. Cleaved N-WASP was then applied to a Source $15 \mathrm{~S}$ column using a gradient of $110 \rightarrow 410 \mathrm{mM} \mathrm{NaCl}$ in $20 \mathrm{mM}$ imidazole, pH 7, $1 \mathrm{mM}$ DTT. Fractions containing N-WASP were concentrated using an Amicon Ultra $10 \mathrm{~K}$ concentrator (Millipore), passed through an SD200 column, concentrated and flash-frozen in $25 \mathrm{mM} \mathrm{Hepes,} \mathrm{pH} \mathrm{7.5,} 150 \mathrm{mM} \mathrm{NaCl}$, and $1 \mathrm{mM} \beta$ BME. N-WASP (BPVCA with single cysteine) and Nck (cysteine-modified, see Table 1) were labeled with Alexa488/568/647. For labeling purposes, the pure protein after Source15S was desalted into a buffer without reducing agent $(25 \mathrm{mM}$ Hepes, $\mathrm{pH} 7,150 \mathrm{mM} \mathrm{NaCl})$ and reacted with a maleimideconjugated fluorophore for $2 \mathrm{hr}$ at room temperature. The reaction was quenched with DTT and the fluorophore was removed using a Source $15 \mathrm{Q}$ and SD75/Hi-trap desalting columns.

$\mathrm{His}_{6}$-Lck kinase was expressed from baculovirus in Spodoptera frugiperta (Sf9) cells. Cells were harvested in $50 \mathrm{mM}$ Tris, pH 7.5, $100 \mathrm{mM} \mathrm{NaCl}, 5 \mathrm{mM} \mathrm{\beta ME}$ and 0.01\% NP-40, $1 \mathrm{mM} \mathrm{PMSF}, 1 \mu \mathrm{g} / \mathrm{ml}$ antipain, $1 \mathrm{mM}$ benzamidine, and $1 \mathrm{\mu g} / \mathrm{ml}$ leupeptin. Cells were lysed by douncing on ice 10 times. The cleared lysate was applied to Ni-NTA agarose beads equilibrated with $20 \mathrm{mM}$ Tris, pH 7.5, $500 \mathrm{mM}$ $\mathrm{NaCl}, 20 \mathrm{mM}$ imidazole, $5 \mathrm{mM} \beta \mathrm{ME}$, and 10\% glycerol (Buffer A), washed with Buffer A containing $1 \mathrm{M}$ $\mathrm{NaCl}$, and then eluted with Buffer A containing $200 \mathrm{mM}$ imidazole 7.5 and $100 \mathrm{mM} \mathrm{NaCl}$. The elute was applied to a Source $15 \mathrm{Q}$ column using a gradient of $100 \rightarrow 300 \mathrm{mM} \mathrm{NaCl}$ in $25 \mathrm{mM}$ Hepes, $\mathrm{pH} 7.5$, and $2 \mathrm{mM} \beta \mathrm{MME}$. Collected fractions were concentrated (Amicon $10 \mathrm{~K}$, Millipore) and applied to an SD75 column in $25 \mathrm{mM}$ Hepes, $\mathrm{pH} 7.5,150 \mathrm{mM} \mathrm{NaCl}$, and $1 \mathrm{mM} \mathrm{\beta ME}$.

\section{Supported lipid bilayers}

Liposomes were prepared as follows. A mixture of 99\% DOPC and 1\% Ni²+-NTA DOGS (Avanti Polar Lipids, Alabaster, Alabama) was dried under argon and further dried under vacuum overnight. The dried mixture was hydrated with MilliO water for $3 \mathrm{hr}$. Buffer $(25 \mathrm{mM}$ Hepes, $\mathrm{pH}$ 7.5, $150 \mathrm{mM} \mathrm{NaCl}, 1 \mathrm{mM} \mathrm{MgCl}$ ) was added to the hydrated multi-lamellar vesicle solution. Small unilamellar vesicles (SUVs) were prepared by 21 passes through an extruder (Avanti) fitted with $80 \mathrm{~nm}$ and again seven times with a fresh $80 \mathrm{~nm}$ or $30 \mathrm{~nm}$ filter. In our hands, changing the filter and re-extruding produced more consistently homogeneous liposomes. SUVs made by this method were stored at $4^{\circ} \mathrm{C}$ and used within 2 days of extrusion.

To make supported lipid bilayers, chambered glass coverslips (Lab-tek, Cat \#155409) were cleaned with $50 \%$ isopropanol, washed with Milli-Q water, and then incubated for $2 \mathrm{hr}$ in $6 \mathrm{M} \mathrm{NaOH}$. We found that cleaning the glass and using it within the few hours after cleaning was important to get consistent fluidity of the supported bilayers. Therefore, all experiments were performed within $8 \mathrm{hr}$ of cleaning the glass substrate. After extensive further washes with Milli-Q water, $150 \mu \mathrm{l}$ of room temperature SUV solution containing 0.5 to $1 \mathrm{mg} / \mathrm{ml}$ lipid was added to the coverslips and incubated for $10 \mathrm{~min}$. Unadsorbed vesicles were removed by a three-step wash totaling a 216-fold dilution. BSA, 0.1\% (Sigma A3294, protease-free, St. Louis, MO) in $25 \mathrm{mM}$ Hepes, pH 7.5, $150 \mathrm{mM} \mathrm{NaCl}, 1 \mathrm{mM} \mathrm{MgCl}$, was used to block the surface for $45 \mathrm{~min}$, yielding a total solution volume of $200 \mu \mathrm{l}$. The surface was washed again with 25 $\mathrm{mM}$ Hepes, $\mathrm{pH} 7.5,150 \mathrm{mM} \mathrm{NaCl}, 1 \mathrm{mM} \mathrm{MgCl}$, and 0.1\% BSA in two steps totaling a 36-fold dilution. $\mathrm{His}_{8}-\mathrm{p}-\mathrm{Nephrin}$ was added to the bilayer at $100 \mathrm{nM}$ and incubated for $1 \mathrm{hr}$ and washed twice totaling a 36 -fold dilution. This procedure yielded $200 \mu$ solution above the bilayer containing $2.8 \mathrm{nM} \mathrm{His}$-pNephrin (assuming a negligible fraction of the total protein binds the bilayer). Subsequent experiments were performed after waiting 30 min to allow the $\mathrm{His}_{8}$ attachment to the bilayer to stabilize (Figure 2figure supplement 1D). Precise control of the timing and dilution-factor of all wash steps was critical to obtaining consistent p-Nephrin densities on the bilayers (quantified as described below). All experiments were performed in $25 \mathrm{mM}$ Hepes, $\mathrm{pH} 7.5,150 \mathrm{mM} \mathrm{NaCl}, 1 \mathrm{mM} \mathrm{MgCl}, 1 \mathrm{mM} \mathrm{BME}$, and 0.1\% BSA.

\section{Measurement of nephrin density on supported lipid bilayers}

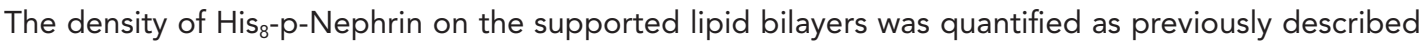
(Galush et al., 2008; Salaita et al., 2010). Briefly, SUVs containing fluorescent lipid (OG-DHPE, Invitrogen) 
were made as described above and were used to generate a standard curve of OG-DHPE concentration vs fluorescence intensity on a Nikon Eclipse Ti microscope using a 20x objective focusing deep into the solution and away from the glass (Figure 2-figure supplement 1A). The slope of the standard curve was denoted as I-labeled SUV. Using the identical settings, a similar standard curve was made using $\mathrm{His}_{8}$-p-Nephrin-Alexa488 in solution, with slope I-labeled protein (Figure 2-figure supplement 1B). I-labeled protein was identical in the presence or absence of Ni-NTA-containing SUVs at 9.5 $\mu \mathrm{M}$ Ni-NTA concentration (minimum of 158-fold excess over $\mathrm{His}_{8}$-p-Nephrin), showing that the His 8 -p-Nephrin-Alexa488 fluorescence does not change upon binding lipid. The correction factor $F$, denoted by $\mathrm{F}=$ I-labeled protein/l-labeled SUV, represents the intrinsic brightness of and sensitivity of

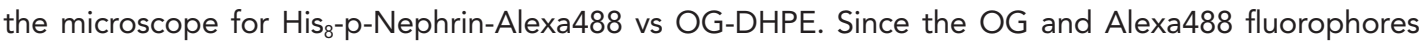
have very similar excitation and emission spectra, $\mathrm{F}$ should be an instrument-independent parameter.

The SUVs containing OG-DHPE were combined in different ratios with non-fluorescent SUVs to make supported bilayers with OG-DHPE densities between 0.05 and $0.4 \%$. Assuming the surface area of the lipid head groups to be $69 \AA^{2}$ (Kucerka et al., 2005), this corresponded to OG-DHPE densities of 1430-11,440 molecules/ $\mu \mathrm{m}^{2}$. A standard curve of bilayer fluorescence intensity on a Nikon Eclipse Ti microscope and a $100 \times$ objective vs fluorophore density was then generated from these bilayers. To obtain the density of $\mathrm{His}_{8}$-p-Nephrin-Alexa488 on the supported bilayers, the measured fluorescence intensity was first divided by $F$, and the result was analyzed with the standard curve of bilayers with OG-DHPE (Figure 2-figure supplement 1C). We note that this approach assumes that $F$ is the same on the SLB as when His - -p-Nephrin-Alexa488 and OG-DHPE are associated with SUVs in free solution.

To examine the potential changes in Alexa488 fluorescence as a function of p-Nephrin density, we generated supported bilayers as above with 10-100\% Alexa488-labeled p-Nephrin. Intensity remained linear up to $\sim 60 \%$ labeling. Initial measurements suggested that the density change in p-bephrin upon clustering is fourfold. Therefore, we used p-Nephrin labeled with $15 \%$ or less Alexa488 for all quantitative image analyses.

\section{Critical concentration measurements}

For critical concentration of clustering measurements, images were collected on a Nikon Eclipse Ti microscope equipped with an Andor iXon Ultra 897 EM-CCD camera, with a 100x objective in epi-fluorescence mode. Background was collected with supported bilayers containing non-fluorescent lipids and subtracted from all images before processing. Images were corrected for uneven illumination and detector sensitivity as previously described (Wu et al., 2008). Briefly, pixel intensities across a homogeneous bilayer containing $\mathrm{p}$-NephrinA488 were normalized to the maximum intensity of the image to obtain pixel-by-pixel correction factors (in a 0 to 1 range). Experimental images were then corrected by dividing by these factors.

Images were thresholded using the triangle algorithm in Image J. The fractional intensity of the clustered regions was then calculated by dividing the integrated intensity of the thresholded image by that of the non-thresholded image. Analyzing the clusters using the triangle algorithm or the Maximum Entropy algorithm yielded the same critical concentrations. Similar thresholding results were obtained using an iterative manual procedure to identify pixels with intensity greater than three standard deviations above the mean of the non-clustered regions. Thus, our calculation of fractional intensity in the clustered regions and our consequent determination of critical concentration are not dependent on the method used to identify clusters.

\section{Size distribution and spatial distribution analyses}

For the data in Figure 2B,C, 512 by 512 pixel images were taken at 93 randomly selected areas of a sample with clusters made using p-NephrinA488, $1 \mu \mathrm{M}$ Nck, and $1 \mu \mathrm{M} N$-WASP. The images were background corrected as described above, flattened using the rolling-ball method in ImageJ, and thresholded using the triangle method. The clusters were binned according to size (excluding those at the image edges) and the distribution was fit to a single-exponential using Graph-pad Prism. The size distributions in Figure 3B were determined similarly from single images obtained at each time point.

To analyze the spatial distribution of puncta, each thresholded image was divided into 25 boxes. In each box, the number of clusters was counted twice-excluding and including clusters at the edges. The average number of edge clusters was obtained from the difference in these values, averaged across all boxes in all images. To eliminate overcounting, for each box half of this value was subtracted 
from the number of clusters counted including edges. These data were plotted to obtain a frequency histogram using Graph-pad Prism and fit to a Gaussian distribution.

\section{Fluorescence recovery after photobleaching (FRAP)}

FRAP was performed using a Nikon Eclipse Ti microscope equipped with an Andor iXon Ultra EM-CCD camera. A circle of 1- $\mu \mathrm{m}$ diameter was initially photobleached and recovery followed for up to $1000 \mathrm{~s}$. The images were corrected for drift using the Sift-Align plugin in ImageJ (Schneider et al., 2012). Background photobleaching was obtained by imaging under the same conditions, excluding the laser illumination used for photobleaching. Background corrected images were normalized to the intensities of the pre-bleached images and fit to either a single or a double-exponential using Graph-pad Prism. F-tests performed in Prism demonstrated that the double-exponential fits are most appropriate ( $p$-values for all experiments were $<0.0001$, Table 2). In the FRAP experiments, a glucose-oxidase scavenger system with trolox was used to reduce photobleaching during the recovery period. $\mathrm{His}_{8}-\mathrm{p}$ NephrinA488 dissociation from the membrane was monitored by the decrease in total fluorescence measured in TIRF mode following washes that afforded a final solution concentration of $2.8 \mathrm{nM}$ (see 'Supported lipid bilayers' section above). To limit the effect of photobleaching, the images at each time point were taken at a different area of the bilayer. The data were fit to a single-exponential with time constant of $2080 \mathrm{~s}$.

\section{Actin assembly assays}

Actin and Arp2/3 complex were purified from rabbit muscle and bovine thymus, respectively, using established methods (Doolittle et al., 2013a; Doolittle et al., 2013b). G-actin (1 $\mu$ M, 10\% rhodamine labeled) was added to p-Nephrin clusters containing $1 \mu \mathrm{M}$ Nck and $2 \mu \mathrm{M} N$-WASP, with or without $10 \mathrm{nM}$ Arp2/3 complex. Images were collected in TIRF mode every 3 min.

For quantitative analysis, images were background corrected and thresholded as described above. In the $\mathrm{p}$-Nephrin clusters, the average intensities of $\mathrm{p}$-Nephrin and rhodamine-actin were measured for times up to $27 \mathrm{~min}$. For each cluster, $\mathrm{t}_{1 / 2}$ represents the time at which the average actin intensity reaches half its maximum value.

\section{Isothermal titration calorimetry}

ITC was performed using a VP-ITC 200 calorimeter (GE Healthcare). Before the experiment, the proteins were dialyzed in the same buffer $(25 \mathrm{mM} \mathrm{Hepes,} \mathrm{pH} 7.5,150 \mathrm{mM} \mathrm{NaCl}, 1 \mathrm{mM} \mathrm{MgCl}$, and $2 \mathrm{mM}$ TCEP). Nck at $150 \mu \mathrm{M}$ in the syringe was titrated to either triply phosphorylated Nephrin or triply phosphorylated TIR. We assumed that all the three sites in Nephrin were of equal affinity. Isotherms were fit well using NITPIC (Keller et al., 2012) and Sedphat (Houtman et al., 2007), assuming that all three pTyr sites in p-Nephrin have equal affinity for Nck.

\section{Acknowledgements}

We thank Kate-Luby Phelps, Abhijit Bugde, and Karen Rothberg at the UTSW Live Cell Imaging Facility for advice on imaging; Louis Kerr at the Marine Biology Laboratory for his assistance in getting started at MBL; Xiaolei Su, Markus Taylor, Ron Vale, Julia Rumpf, Jack Taunton, and other participants in the MBL/HHMI Summer Institute for advice and discussion regarding imaging and supported lipid bilayers; Jitu Mayor for discussions regarding phase transitions and membrane organization; Khuloud Jaqaman for advice on image analyses; Chad Brautigam and Thomas Scheuermann at the UTSW

Table 2. Statistics of fitting for FRAP data

\begin{tabular}{lllll} 
& p-Nephrin & Nck (with p-Nephrin) & Nck (with p-TIR) & N-WASP \\
\hline Null hypothesis & Single Exp. & Single Exp. & Single Exp. & Single Exp. \\
\hline Alternate hypothesis & Double Exp. & Double Exp. & Double Exp. & Double Exp. \\
\hline p value & $<0.0001$ & $<0.0001$ & $<0.0001$ & $<0.0001$ \\
\hline Conclusion (alpha $=0.05)$ & Reject null hypo. & Reject null hypo. & Reject null hypo. & Reject null hypo. \\
\hline Preferred model & Double Exp. & Double Exp. & Double Exp. & Double Exp. \\
\hline F (DFn, DFd) & $64.16(2282)$ & $47.33(2635)$ & $46.72(2379)$ & $48.64(2379)$ \\
\hline
\end{tabular}

DOI: 10.7554/eLife.04123.024 
Molecular Biophysics Resource for assistance with ITC; Salman Banani, Jonathan Ditlev, Soyeon Kim, and Shae Padrick for critical reading of the manuscript; and members of the Rosen lab for helpful discussions.

\section{Additional information}

Funding

\begin{tabular}{lll} 
Funder & Grant reference number & Author \\
\hline Howard Hughes Medical Institute & $\begin{array}{l}\text { HHMI Collaborative } \\
\text { Innovations Award (Work } \\
\text { performed at MBL/HHMI }\end{array}$ & Michael Rosen \\
Summer Institute) & Michael Rosen \\
\hline $\begin{array}{l}\text { National Institute of General } \\
\text { Medical Sciences }\end{array}$ & R01-GM56322 & Michael Rosen \\
\hline Welch Foundation & I-1544 & Michael Rosen \\
\hline Chilton Foundation & &
\end{tabular}

The funders had no role in study design, data collection and interpretation, or the decision to submit the work for publication.

Author contributions

SB, Conception and design, Acquisition of data, Analysis and interpretation of data, Drafting or revising the article; MKR, Conception and design, Analysis and interpretation of data, Drafting or revising the article

\section{References}

Abmayr SM, Pavlath GK. 2012. Myoblast fusion: lessons from flies and mice. Development 139:641-656. doi: 10.1242/dev.068353.

Antoku S, Saksela K, Rivera GM, Mayer BJ. 2008. A crucial role in cell spreading for the interaction of Abl PxxP motifs with Crk and Nck adaptors. Journal of Cell Science 121:3071-3082. doi: 10.1242/jcs.031575.

Balagopalan L, Barr VA, Kortum RL, Park AK, Samelson LE. 2013. Cutting edge: cell surface linker for activation of $T$ cells is recruited to microclusters and is active in signaling. Journal of Immunology 190:3849-3853. doi: 10.4049/jimmunol.1202760.

Bergman A, Condeelis JS, Gligorijevic B. 2014. Invadopodia in context. Cell Adhesion \& Migration 8:273-279. doi: 10.4161/cam.28349.

Blasutig IM, New LA, Thanabalasuriar A, Dayarathna TK, Goudreault M, Quaggin SE, Li SS, Gruenheid S, Jones N, Pawson T. 2008. Phosphorylated YDXV motifs and Nck SH2/SH3 adaptors act cooperatively to induce actin reorganization. Molecular and Cellular Biology 28:2035-2046. doi: 10.1128/MCB.01770-07.

Briegel A, Li X, Bilwes AM, Hughes KT, Jensen GJ, Crane BR. 2012. Bacterial chemoreceptor arrays are hexagonally packed trimers of receptor dimers networked by rings of kinase and coupling proteins. Proceedings of the National Academy of Sciences of USA 109:3766-3771. doi: 10.1073/pnas.1115719109.

Briegel A, Wong ML, Hodges HL, Oikonomou CM, Piasta KN, Harris MJ, Fowler DJ, Thompson LK, Falke JJ, Kiessling LL, Jensen GJ. 2014. New insights into bacterial chemoreceptor array structure and assembly from electron cryotomography. Biochemistry 53:1575-1585. doi: 10.1021/bi5000614.

Buday L, Wunderlich L, Tamas P. 2002. The Nck family of adapter proteins: regulators of actin cytoskeleton. Cellular Signalling 14:723-731. doi: 10.1016/S0898-6568(02)00027-X.

Burke NA, Takimoto K, Li D, Han W, Watkins SC, Levitan ES. 1999. Distinct structural requirements for clustering and immobilization of K+ channels by PSD-95. The Journal of General Physiology 113:71-80. doi: 10.1085/ jgp.113.1.71.

Campellone KG, Giese A, Tipper DJ, Leong JM. 2002. A tyrosine-phosphorylated 12-amino-acid sequence of enteropathogenic Escherichia coli Tir binds the host adaptor protein Nck and is required for Nck localization to actin pedestals. Molecular Microbiology 43:1227-1241. doi: 10.1046/j.1365-2958.2002.02817.x.

Chaki SP, Rivera GM. 2013. Integration of signaling and cytoskeletal remodeling by Nck in directional cell migration. Bioarchitecture 3:57-63. doi: 10.4161/bioa.25744.

Chen WV, Maniatis T. 2013. Clustered protocadherins. Development 140:3297-3302. doi: 10.1242/dev.090621.

Clayton AH, Orchard SG, Nice EC, Posner RG, Burgess AW. 2008. Predominance of activated EGFR higher-order oligomers on the cell surface. Growth Factors 26:316-324. doi: 10.1080/08977190802442187.

Derivery E, Sousa C, Gautier JJ, Lombard B, Loew D, Gautreau A. 2009. The Arp2/3 activator WASH controls the fission of endosomes through a large multiprotein complex. Developmental Cell 17:712-723. doi: 10.1016/j.devcel.2009.09.010. 
Dill KA, Bromberg S. 2003. Molecular driving forces: statistical thermodynamics in chemistry and biology. 2nd ed. New York: Garland Science.

Ditlev JA, Michalski PJ, Huber G, Rivera GM, Mohler WA, Loew LM, Mayer BJ. 2012. Stoichiometry of Nck-dependent actin polymerization in living cells. The Journal of Cell Biology 197:643-658. doi: 10.1083/ jcb.201111113.

Doolittle LK, Rosen MK, Padrick SB. 2013a. Measurement and analysis of in vitro actin polymerization. Methods in Molecular Biology 1046:273-293. doi: 10.1007/978-1-62703-538-5_16.

Doolittle LK, Rosen MK, Padrick SB. 2013b. Purification of Arp2/3 complex from Saccharomyces cerevisiae. Methods in Molecular Biology 1046:251-271. doi: 10.1007/978-1-62703-538-5_15.

Douglass AD, Vale RD. 2005. Single-molecule microscopy reveals plasma membrane microdomains created by protein-protein networks that exclude or trap signaling molecules in T cells. Cell 121:937-950. doi: 10.1016/j. cell.2005.04.009.

Dustin ML, Chakraborty AK, Shaw AS. 2010. Understanding the structure and function of the immunological synapse. Cold Spring Harbor Perspectives in Biology 2:a002311. doi: 10.1101/cshperspect.a002311.

Galush WJ, Nye JA, Groves JT. 2008. Quantitative fluorescence microscopy using supported lipid bilayer standards. Biophysical Journal 95:2512-2519. doi: 10.1529/biophysj.108.131540.

Gerke P, Huber TB, Sellin L, Benzing T, Walz G. 2003. Homodimerization and heterodimerization of the glomerular podocyte proteins nephrin and NEPH1. Journal of the American Society of Nephrology 14:918-926. doi: 10.1097/01.ASN.0000057853.05686.89.

Goldstein B, Perelson AS. 1984. Equilibrium-theory for the clustering of bivalent cell-surface receptors by trivalent ligands - application to histamine-release from basophils. Biophysical Journal 45:1109-1123. doi: 10.1016/S0006-3495(84)84259-9.

Gomez TS, Billadeau DD. 2009. A FAM21-containing WASH complex regulates retromer-dependent sorting. Developmental Cell 17:699-711. doi: 10.1016/j.devcel.2009.09.009.

Goswami D, Gowrishankar K, Bilgrami S, Ghosh S, Raghupathy R, Chadda R, Vishwakarma R, Rao M, Mayor S. 2008. Nanoclusters of GPI-anchored proteins are formed by cortical actin-driven activity. Cell 135:1085-1097. doi: 10.1016/j.cell.2008.11.032.

Gowrishankar K, Ghosh S, Saha S, C R, Mayor S, Rao M. 2012. Active remodeling of cortical actin regulates spatiotemporal organization of cell surface molecules. Cell 149:1353-1367. doi: 10.1016/j.cell.2012.05.008.

Grecco HE, Schmick M, Bastiaens PI. 2011. Signaling from the living plasma membrane. Cell 144:897-909. doi: 10.1016/j.cell.2011.01.029.

Greenfield D, McEvoy AL, Shroff H, Crooks GE, Wingreen NS, Betzig E, Liphardt J. 2009. Self-organization of the Escherichia coli chemotaxis network imaged with super-resolution light microscopy. PLOS Biology 7:e1000137. doi: 10.1371/journal.pbio.1000137.

Henkler F, Behrle E, Dennehy KM, Wicovsky A, Peters N, Warnke C, Pfizenmaier K, Wajant H. 2005. The extracellular domains of FasL and Fas are sufficient for the formation of supramolecular FasL-Fas clusters of high stability. The Journal of Cell Biology 168:1087-1098. doi: 10.1083/jcb.200501048.

Himanen JP, Saha N, Nikolov DB. 2007. Cell-cell signaling via Eph receptors and ephrins. Current Opinion in Cell Biology 19:534-542. doi: 10.1016/j.ceb.2007.08.004.

Hoffmann JE, Fermin Y, Stricker RL, Ickstadt K, Zamir E. 2014. Symmetric exchange of multi-protein building blocks between stationary focal adhesions and the cytosol. eLife 3:e02257. doi: 10.7554/eLife.02257.

Houtman JC, Brown PH, Bowden B, Yamaguchi H, Appella E, Samelson LE, Schuck P. 2007. Studying multisite binary and ternary protein interactions by global analysis of isothermal titration calorimetry data in SEDPHAT: application to adaptor protein complexes in cell signaling. Protein Science 16:30-42. doi: 10.1110/ps.062558507.

Houtman JC, Yamaguchi H, Barda-Saad M, Braiman A, Bowden B, Appella E, Schuck P, Samelson LE. 2006. Oligomerization of signaling complexes by the multipoint binding of GRB2 to both LAT and SOS1. Nature Structural \& Molecular Biology 13:798-805. doi: 10.1038/nsmb1133.

Hunter T. 2000. Signaling-2000 and beyond. Cell 100:113-127. doi: 10.1016/S0092-8674(00)81688-8.

James JR, Vale RD. 2012. Biophysical mechanism of T-cell receptor triggering in a reconstituted system. Nature 487:64-69. doi: 10.1038/nature11214.

Jia D, Gomez TS, Billadeau DD, Rosen MK. 2012. Multiple repeat elements within the FAM21 tail link the WASH actin regulatory complex to the retromer. Molecular Biology of the Cell 23:2352-2361. doi: 10.1091/mbc.E11-12-1059.

Jia D, Gomez TS, Metlagel Z, Umetani J, Otwinowski Z, Rosen MK, Billadeau DD. 2010. WASH and WAVE actin regulators of the Wiskott-Aldrich syndrome protein (WASP) family are controlled by analogous structurally related complexes. Proceedings of the National Academy of Sciences of USA 107:10442-10447. doi: 10.1073/ pnas.0913293107.

Jones N, Blasutig IM, Eremina V, Ruston JM, Bladt F, Li H, Huang H, Larose L, Li SS, Takano T, Quaggin SE, Pawson T. 2006. Nck adaptor proteins link nephrin to the actin cytoskeleton of kidney podocytes. Nature 440:818-823. doi: 10.1038/nature04662.

Jones N, New LA, Fortino MA, Eremina V, Ruston J, Blasutig IM, Aoudjit L, Zou Y, Liu X, Yu GL, Takano T, Quaggin SE, Pawson T. 2009. Nck proteins maintain the adult glomerular filtration barrierg. Journal of the American Society of Nephrology 20:1533-1543. doi: 10.1681/ASN.2009010056.

Kaipa BR, Shao H, Schafer G, Trinkewitz T, Groth V, Liu J, Beck L, Bogdan S, Abmayr SM, Önel SF. 2013. Dock mediates Scar- and WASp-dependent actin polymerization through interaction with cell adhesion molecules in founder cells and fusion-competent myoblasts. Journal of Cell Science 126:360-372. doi: $10.1242 /$ jcs.113860. 
Kaushansky A, Gordus A, Chang B, Rush J, MacBeath G. 2008. A quantitative study of the recruitment potential of all intracellular tyrosine residues on EGFR, FGFR1 and IGF1R. Molecular Biosystems 4:643-653. doi: 10.1039/ b801018h.

Keller S, Vargas C, Zhao H, Piszczek G, Brautigam CA, Schuck P. 2012. High-precision isothermal titration calorimetry with automated peak-shape analysis. Analytical Chemistry 84:5066-5073. doi: 10.1021/ac3007522.

Kucerka N, Tristram-Nagle S, Nagle JF. 2005. Structure of fully hydrated fluid phase lipid bilayers with monounsaturated chains. The Journal of Membrane Biology 208:193-202. doi: 10.1007/s00232-005-7006-8.

Lee KH, Dinner AR, Tu C, Campi G, Raychaudhuri S, Varma R, Sims TN, Burack WR, Wu H, Wang J, Kanagawa O, Markiewicz M, Allen PM, Dustin ML, Chakraborty AK, Shaw AS. 2003. The immunological synapse balances T cell receptor signaling and degradation. Science 302:1218-1222. doi: 10.1126/science.1086507.

Lettau M, Pieper J, Janssen O. 2009. Nck adapter proteins: functional versatility in T cells. Cell Communication and Signaling 7:1. doi: 10.1186/1478-811X-7-1.

Li M, Khursigara CM, Subramaniam S, Hazelbauer GL. 2011. Chemotaxis kinase CheA is activated by three neighbouring chemoreceptor dimers as effectively as by receptor clusters. Molecular Microbiology 79:677-685. doi: 10.1111/j.1365-2958.2010.07478.x.

Li P, Banjade S, Cheng HC, Kim S, Chen B, Guo L, Llaguno M, Hollingsworth JV, King DS, Banani SF, Russo PS, Jiang QX, Nixon BT, Rosen MK. 2012. Phase transitions in the assembly of multivalent signalling proteins. Nature 483:336-340. doi: 10.1038/nature10879.

Lingwood D, Simons K. 2010. Lipid rafts as a membrane-organizing principle. Science 327:46-50. doi: 10.1126/ science.1174621.

Machesky LM, Mullins RD, Higgs HN, Kaiser DA, Blanchoin L, May RC, Hall ME, Pollard TD. 1999. Scar, a WASprelated protein, activates nucleation of actin filaments by the Arp2/3 complex. Proceedings of the National Academy of Sciences of USA 96:3739-3744. doi: 10.1073/pnas.96.7.3739.

New LA, Keyvani Chahi A, Jones N. 2013. Direct regulation of nephrin tyrosine phosphorylation by Nck adaptor proteins. The Journal of Biological Chemistry 288:1500-1510. doi: 10.1074/jbc.M112.439463.

Nikolov DB, Xu K, Himanen JP. 2013. Eph/ephrin recognition and the role of Eph/ephrin clusters in signaling initiation. Biochimica et Biophysica Acta 1834:2160-2165. doi: 10.1016/j.bbapap.2013.04.020.

Noy E, Fried S, Matalon O, Barda-Saad M. 2012. WIP remodeling actin behind the Scenes: how WIP Reshapes immune and other functions. International Journal of Molecular Sciences 13:7629-7647. doi: 10.3390/ijms13067629.

Oser M, Mader CC, Gil-Henn H, Magalhaes M, Bravo-Cordero JJ, Koleske AJ, Condeelis J. 2010. Specific tyrosine phosphorylation sites on cortactin regulate Nck1-dependent actin polymerization in invadopodia. Journal of Cell Science 123:3662-3673. doi: 10.1242/jcs.068163.

Padrick SB, Cheng HC, Ismail AM, Panchal SC, Doolittle LK, Kim S, Skehan BM, Umetani J, Brautigam CA, Leong JM, Rosen MK. 2008. Hierarchical regulation of WASP/WAVE proteins. Molecular Cell 32:426-438. doi: 10.1016/j.molcel.2008.10.012.

Padrick SB, Rosen MK. 2010. Physical mechanisms of signal integration by WASP family proteins. Annual Review of Biochemistry 79:707-735. doi: 10.1146/annurev.biochem.77.060407.135452.

Palmer A, Zimmer M, Erdmann KS, Eulenburg V, Porthin A, Heumann R, Deutsch U, Klein R. 2002. EphrinB phosphorylation and reverse signaling: regulation by Src kinases and PTP-BL phosphatase. Molecular Cell 9:725-737. doi: 10.1016/S1097-2765(02)00488-4.

Plowman SJ, Muncke C, Parton RG, Hancock JF. 2005. H-ras, K-ras, and inner plasma membrane raft proteins operate in nanoclusters with differential dependence on the actin cytoskeleton. Proceedings of the National Academy of Sciences of USA 102:15500-15505. doi: 10.1073/pnas.0504114102.

Roche KW, O'Brien RJ, Mammen AL, Bernhardt J, Huganir RL. 1996. Characterization of multiple phosphorylation sites on the AMPA receptor GluR1 subunit. Neuron 16:1179-1188. doi: 10.1016/ S0896-6273(00)80144-0.

Salaita K, Nair PM, Petit RS, Neve RM, Das D, Gray JW, Groves JT. 2010. Restriction of receptor movement alters cellular response: physical force sensing by EphA2. Science 327:1380-1385. doi: 10.1126/ science. 1181729.

Schlessinger J. 2000. Cell signaling by receptor tyrosine kinases. Cell 103:211-225. doi: 10.1016/ S0092-8674(00)00114-8.

Schneider CA, Rasband WS, Eliceiri KW. 2012. NIH Image to ImageJ: 25 years of image analysis. Nature Methods 9:671-675. doi: 10.1038/nmeth.2089.

Scott FL, Stec B, Pop C, Dobaczewska MK, Lee JJ, Monosov E, Robinson H, Salvesen GS, Schwarzenbacher R, Riedl SJ. 2009. The Fas-FADD death domain complex structure unravels signalling by receptor clustering. Nature 457:1019-1022. doi: 10.1038/nature07606.

Seiradake E, Schaupp A, del Toro Ruiz D, Kaufmann R, Mitakidis N, Harlos K, Aricescu AR, Klein R, Jones EY. 2013. Structurally encoded intraclass differences in EphA clusters drive distinct cell responses. Nature Structural \& Molecular Biology 20:958-964. doi: 10.1038/nsmb.2617.

Sharma P, Varma R, Sarasij RC, Ira GK, Krishnamoorthy G, Rao M, Mayor S. 2004. Nanoscale organization of multiple GPI-anchored proteins in living cell membranes. Cell 116:577-589. doi: 10.1016/S0092-8674(04)00167-9.

Siegel RM, Muppidi JR, Sarker M, Lobito A, Jen M, Martin D, Straus SE, Lenardo MJ. 2004. SPOTS: signaling protein oligomeric transduction structures are early mediators of death receptor-induced apoptosis at the plasma membrane. The Journal of Cell Biology 167:735-744. doi: 10.1083/jcb.200406101.

Varma R, Mayor S. 1998. GPI-anchored proteins are organized in submicron domains at the cell surface. Nature 394:798-801. doi: 10.1038/29563. 
Verma R, Kovari I, Soofi A, Nihalani D, Patrie K, Holzman LB. 2006. Nephrin ectodomain engagement results in Src kinase activation, nephrin phosphorylation, Nck recruitment, and actin polymerization. The Journal of Clinical Investigation 116:1346-1359. doi: 10.1172/JCI27414.

Wagner MJ, Stacey MM, Liu BA, Pawson T. 2013. Molecular mechanisms of SH2- and PTB-domaincontaining proteins in receptor tyrosine kinase signaling. Cold Spring Harbor Perspectives in Biology 5:a008987. doi: 10.1101/cshperspect.a008987.

Wang L, Yang JK, Kabaleeswaran V, Rice AJ, Cruz AC, Park AY, Yin Q, Damko E, Jang SB, Raunser S, Robinson CV, Siegel RM, Walz T, Wu H. 2010. The Fas-FADD death domain complex structure reveals the basis of DISC assembly and disease mutations. Nature Structural \& Molecular Biology 17:1324-1329. doi: 10.1038/nsmb.1920.

Weiner OD, Marganski WA, Wu LF, Altschuler SJ, Kirschner MW. 2007. An actin-based wave generator organizes cell motility. PLOS Biology 5:e221. doi: 10.1371/journal.pbio.0050221.

Welsh GI, Saleem MA. 2010. Nephrin-signature molecule of the glomerular podocyte? The Journal of Pathology 220:328-337. doi: 10.1002/path.2661.

Wiesner S, Helfer E, Didry D, Ducouret G, Lafuma F, Carlier MF, Pantaloni D. 2003. A biomimetic motility assay provides insight into the mechanism of actin-based motility. The Journal of Cell Biology 160:387-398. doi: $10.1083 /$ jcb.200207148.

Wu H. 2013. Higher-order assemblies in a new paradigm of signal transduction. Cell 153:287-292. doi: 10.1016/j. cell.2013.03.013.

Wu JQ, McCormick CD, Pollard TD. 2008. Chapter 9: Counting proteins in living cells by quantitative fluorescence microscopy with internal standards. Methods in Cell Biology 89:253-273. doi: 10.1016/S0091-679X(08)00609-2.

Wu Y, Vendome J, Shapiro L, Ben-Shaul A, Honig B. 2011. Transforming binding affinities from three dimensions to two with application to cadherin clustering. Nature 475:510-513. doi: 10.1038/nature10183.

Yamaguchi H, Lorenz M, Kempiak S, Sarmiento C, Coniglio S, Symons M, Segall J, Eddy R, Miki H, Takenawa T, Condeelis J. 2005. Molecular mechanisms of invadopodium formation: the role of the N-WASP-Arp2/3 complex pathway and cofilin. The Journal of Cell Biology 168:441-452. doi: 10.1083/jcb.200407076.

Yap AS, Brieher WM, Gumbiner BM. 1997. Molecular and functional analysis of cadherin-based adherens junctions. Annual Review of Cell and Developmental Biology 13:119-146. doi: 10.1146/annurev.cellbio.13.1.119.

Zinke-Allmang M, Feldman LC, Grabow MH. 1992. Clustering on surfaces. Surface Science Reports 16:377-463. doi: 10.1016/0167-5729(92)90006-W. 